\title{
New Efficient Submodule for a Modular Multilevel Converter in Multiterminal HVDC Networks
}

\author{
Grain Philip Adam, Member, IEEE, Ibrahim Abdelsalam, John Edward Fletcher, Senior Member, IEEE, \\ Graeme M. Burt, Member, IEEE, Derrick Holliday, and Stephen Jon Finney
}

\begin{abstract}
In high-voltage applications, the magnitude of total semiconductor losses (on-state and switching) determines the viability of modular-type multilevel converters. Therefore, this paper presents a new cell arrangement that aims to lower total semiconductor loss of the modular multilevel converter (MMC) to less than that of the half-bridge modular multilevel converter (HB-MMC). Additional attributes of the proposed cell are: it eliminates the protective thyristors used in conventional half-bridge cells that deviate part of the dc-fault current away from the antiparallel diode of the main switch when the converter is blocked during a de short-circuit fault, and it can facilitate continued operation of the MMC during cell failures without the need for a mechanical bypass switch. Thus, the MMC that uses the proposed cell retains all advantages of the HB-MMC such as full modularity of the power circuit and internal fault management. The claimed attributes of the proposed cell are verified using illustrative simulations and reduced scale experimentations. Additionally, this paper provides brief and critical discussions that highlight the attributes and limitations of popular MMC control methods and different MMC cells structures proposed in the literature, considering the power electronic system perspective.
\end{abstract}

Index Terms-Flying capacitor (FC) cell, half- and full-bridge modular multilevel converter, mixed-cell commutation cells, voltage-source converter high-voltage direct-current (VSC-HVDC) transmission systems.

\section{INTRODUCTION}

$\mathbf{R}$ APID developments of voltage-source converter highvoltage direct-current (VSC-HVDC) transmission systems in recent years have attracted significant research interest in high-voltage high-power converters, dc switchgear, and dc protection systems [1], [2]. At present, half-bridge modular multilevel converters (HB-MMCs) and optimized full-bridge

Manuscript received April 29, 2016; revised June 14, 2016; accepted August 16, 2016. Date of publication August 25, 2016; date of current version February 11, 2017. This work was supported by the Australian Research Council under Discovery Projects funding scheme through Project DP150102368, and in part by the SUPERGEN Hubnet project under Grant EP/I013636/1. Recommended for publication by Associate Editor B. Singh.

G. P. Adam, G. M. Burt, D. Holliday, and S. J. Finney are with the University of Strathclyde, Glasgow G1 1XQ, U.K. (e-mail: grain.adam@ eee.strath.ac.uk; graeme.burt@strath.ac.uk; derrick.holliday@strath.ac.uk; stephen.finney@strath.ac.uk).

I. Abdelsalam is with the University of Strathclyde, Glasgow G1 1XQ, U.K., and also with the Arab Academy for Science and Technology and Maritime Transport, Cairo 1029, Egypt (e-mail: ibrahim.abdallah@strath.ac.uk).

J. E. Fletcher is with the University of New South Wales, Sydney, NSW 2052, Australia (e-mail: john.fletcher@unsw.ed.au).

Color versions of one or more of the figures in this paper are available online at http://ieeexplore.ieee.org.

Digital Object Identifier 10.1109/TPEL.2016.2603180 modular multilevel converters (MMCs)are the preferred choice for industry when designing VSC-HVDC transmission systems with power rating up to $1000 \mathrm{MW}$ per converter [3]-[7]. The reasons are the following: their modularity permits easy incorporation of redundant cells into each arm to facilitate continued operation should a (limited) number of cell capacitors and switching devices fail; offers the best tradeoff between semiconductor loss and performance; and seamless current commutation between converter arms, unlike many of the hybrid converter topologies discussed in [8]-[11].

Fig. 1 summarizes some of the cell arrangements being used, or proposed for use, in modular and hybrid multilevel converters. These cells could be categorized into unipolar cells with two-level or three-level output voltage $\left(V_{c}\right.$ and 0 , and $2 V_{c}, V_{c}$, and 0 , respectively), asymmetrical bipolar cell with four- level output voltage $\left(2 V_{c}, V_{c}, 0\right.$, and $\left.-V_{c}\right)$, and symmetrical bipolar cells with three-level and five-level output voltage $\left(V_{c}, 0\right.$, and $V_{c}$, and $2 V_{c}, V_{c}, 0,-V_{c}$, and $-2 V_{c}$, respectively), assuming that all cell capacitors are well balanced $V_{c 1}=V_{c 2}=V_{c}$. Unipolar cells such as in Fig. 1(a) and (c)-(e) limit the number of semiconductor switches in the conduction path to one or two per cell, and this makes these cells attractive from semiconductor loss point of view. However, the use of unipolar cells limits the operating range of modular converters to unipolar dc-link voltages, with the output phase voltage and voltages developed across the upper and lower arms restricted within the envelope defined by $+1 / 2 V_{\mathrm{dc} 0}$ and $-1 / 2 V_{\mathrm{dc} 0}$, and $V_{\mathrm{dc} 0}$ and 0 , respectively, where $V_{\mathrm{dc} 0}$ represents the nominal dc-link voltage [see Fig. 2(a) and (b)]. These restrictions make MMCs that employ unipolar cells unable to deal with dc faults because their upper and lower arms are unable to produce voltages with opposite polarities to counter or balance the reduced input dc-link voltage as it collapses during dc faults. Recently, there are several attempts to further lower MMC switching loss by adopting three-level unipolar cells such as flying capacitor (FC), T-type, and active neutral-point clamped (ANPC) cells [1], [12]. These three-level cells also reduce the number of $\mathrm{dc}-\mathrm{dc}$ converters required to supply the insulated-gate bipolar transistor (IGBT) gate drives by $50 \%$, thus leading to overall reduction in the cost and weight of the MMC control circuit. However, the use of FC cells in the MMC is not attractive because it compromises the modularity of the power circuit and reliability (each cell contains two floating capacitors with different rated voltages). T-type and ANPC cells require complex capacitor voltage balancing and suffer from high capacitor voltage ripple due to the lack of redundant 


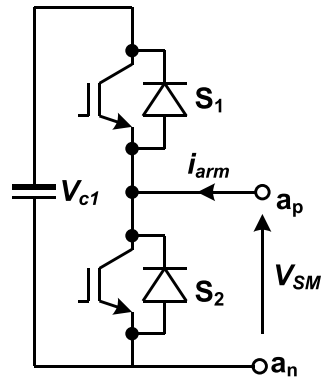

(a)

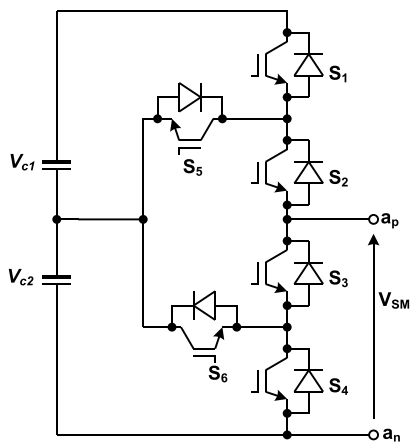

(d)

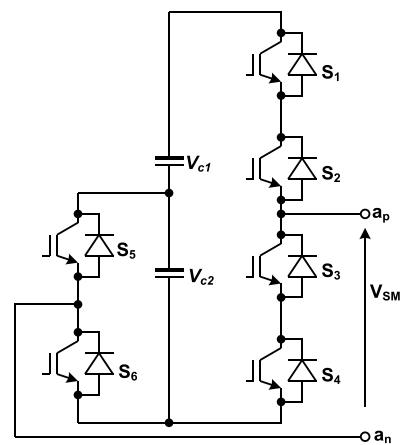

(g)

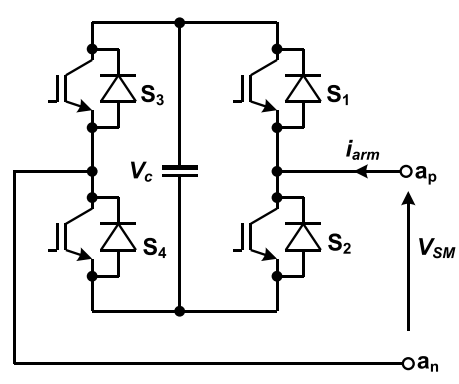

(b)

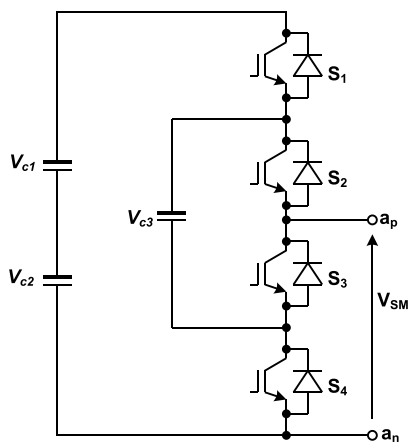

(e)

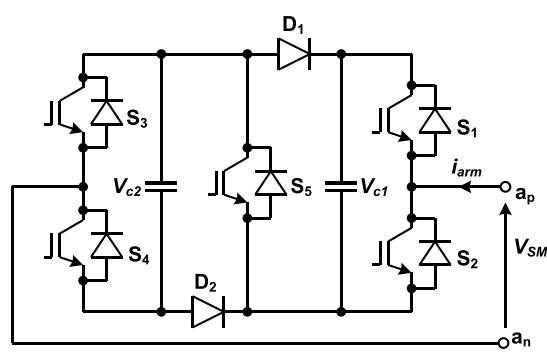

(h)

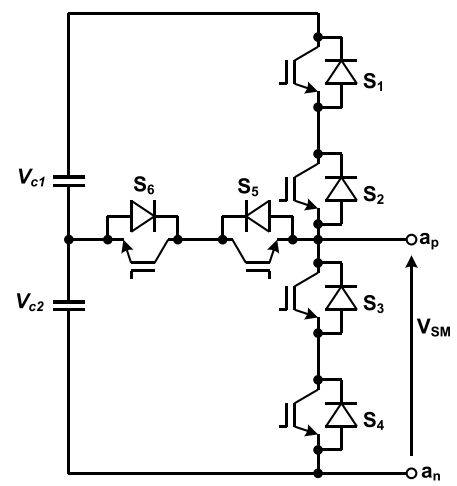

(c)

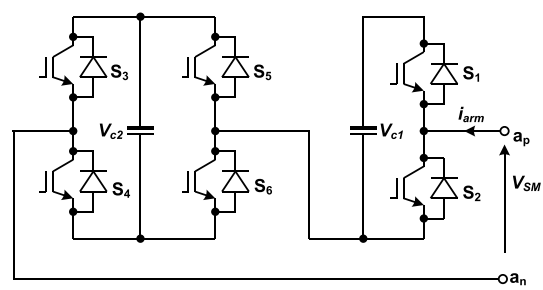

(f)

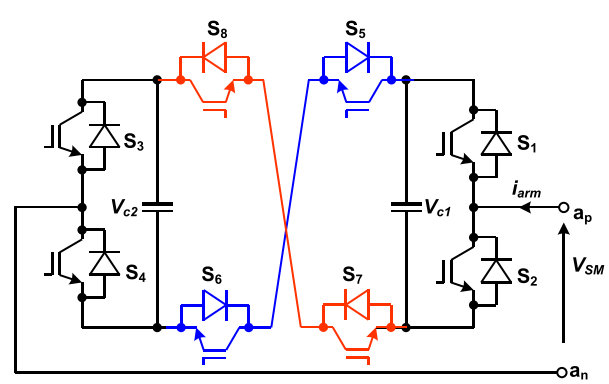

(i)

Fig. 1. Some of the known cell configurations for modular and hybrid multilevel converters. (a) Two-level half-bridge unipolar cell. (b) Three-level full-bridge symmetrical bipolar cell. (c) Three-level T-type unipolar cell. (d) Three-level neutral-point clamped unipolar cell. (e) Three-level flying capacitor unipolar cell. (f) Four-level asymmetric bipolar hybrid cell. (g) Four-level asymmetric bipolar cell. (h) Three-level asymmetric doubled clamped bipolar cell. (i) five-level symmetrical cross-connected bipolar cell.

switch states that can be used to balance the cell capacitor voltages at the cell level (each voltage level can be generated by only one state, and upper capacitor of the cell in Fig. 1(c) and (d) cannot be selected or inserted into the power path unless the lower capacitor is already inserted into power path).

Each asymmetric bipolar cell in Fig. 1(f) and (g) inserts three semiconductor switches in the conduction path per cell during normal operation and can exploit the negative voltage level it generates to allow MMC upper and lower arm voltages to be varied between $V_{\mathrm{dc} 0}$ and 0 during normal operation, and $1 / 2 V_{\mathrm{dc} 0}$ and $-1 / 2 V_{\mathrm{dc} 0}$ during operation with zero dc-link voltage [see Fig. 2(a) and (c)]. Such an operation permits MMC cell capacitor voltages to be regulated independent of the dc-link voltage $\left(V_{\mathrm{dc}}\right)$ and enables MMC upper and lower arms to generate bipolar voltages that can be used to counter the dc-link voltage $\left(V_{\mathrm{dc}}\right)$ as it varies between 0 and $V_{\mathrm{dc} 0}$ (including during dc short-circuit fault). As a result, the MMCs that employ the asymmetrical cells in Fig. 1(f) and (g) are able to deal with dc faults better than those using unipolar cells, while retaining full control over the active and reactive power they exchange with the ac grid [4], [5], [13]. Among the asymmetrical bipolar cells, the hybrid cell in Fig. 1(f) is attractive and has sufficient redundant switch states that allow the cell capacitor voltage of the MMC to be balanced at local or global levels and does not lead 


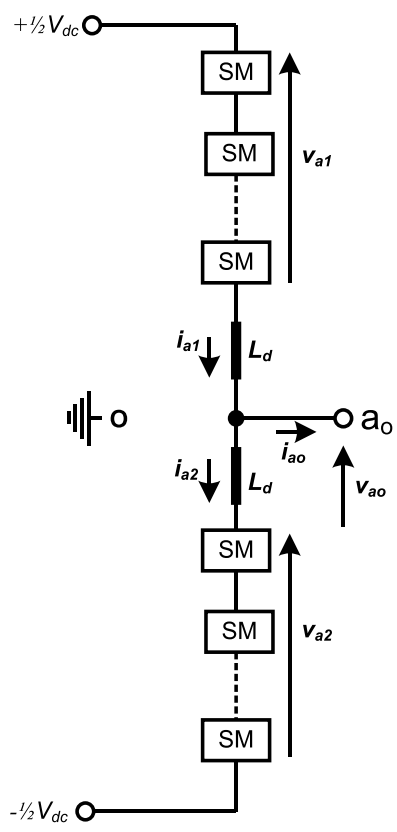

(a)

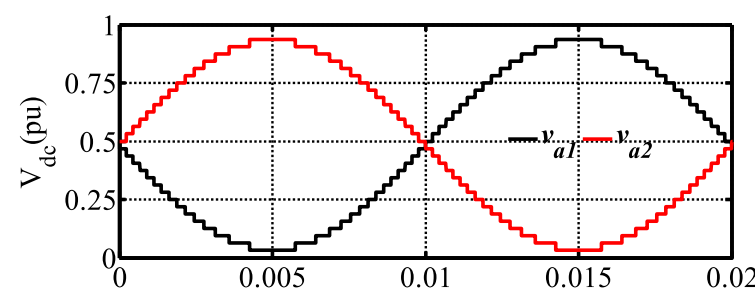

(b)

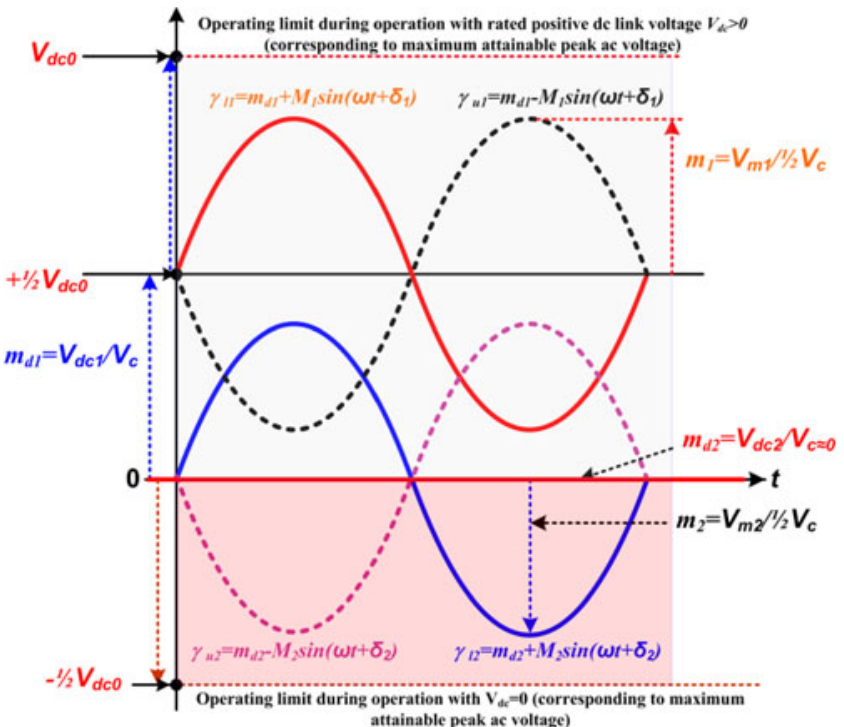

(c)

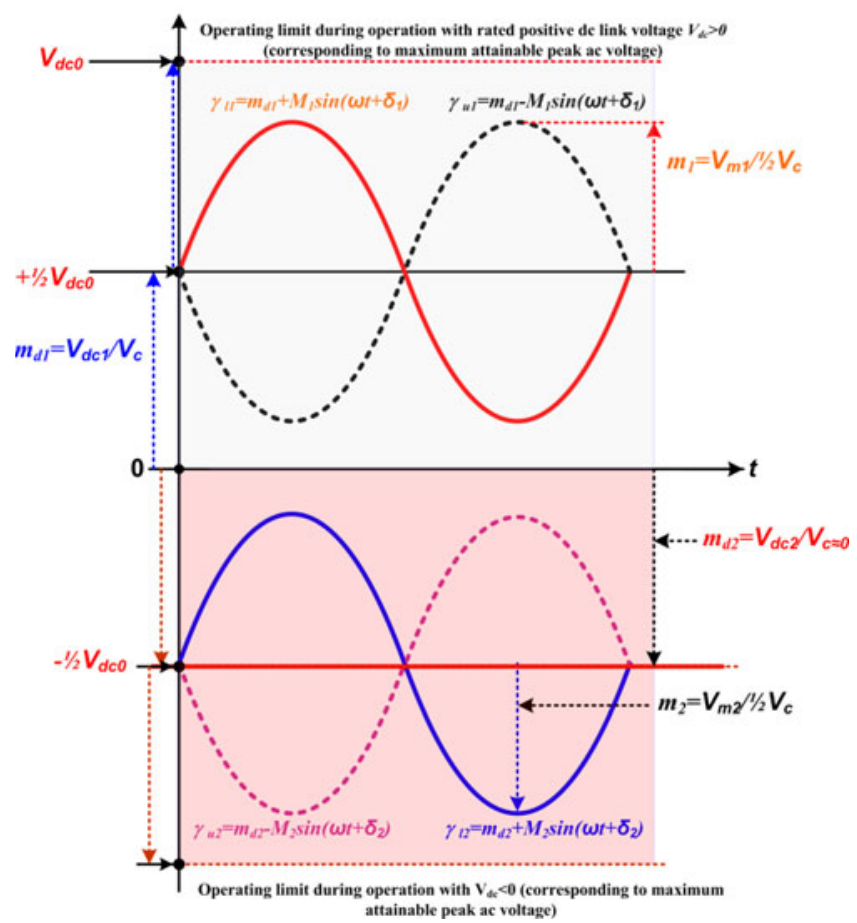

(d)

Fig. 2. Illustration of different operating limits of MMCs that employ unipolar and symmetrical and asymmetrical bipolar cells (vertical axis is normalized by $\left.1 / 2 V_{\mathrm{dc} 0}\right)$. (a) Phase leg of generic MMC. (b) Operational limits of MMCs that employ unipolar cells such as in Fig. 1(a) and (c)-(e). (c) Operational limits of MMCs that employ asymmetric bipolar cells such as in Fig. 1(f)-(h). (d) Operational limits of MMCs that employ symmetric bipolar cells such as in Fig. 1(b) and (i), including possibility of overmodulation. 


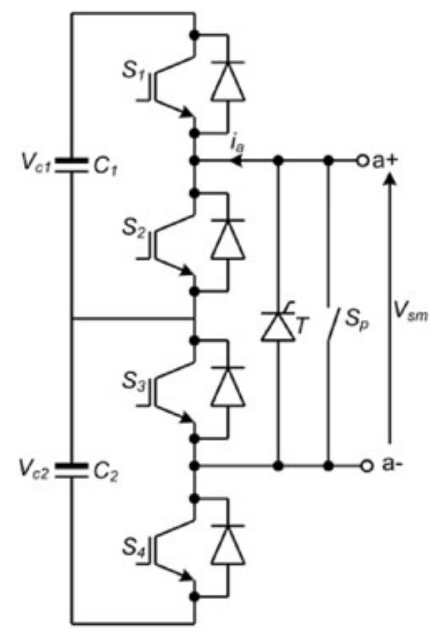

(a)

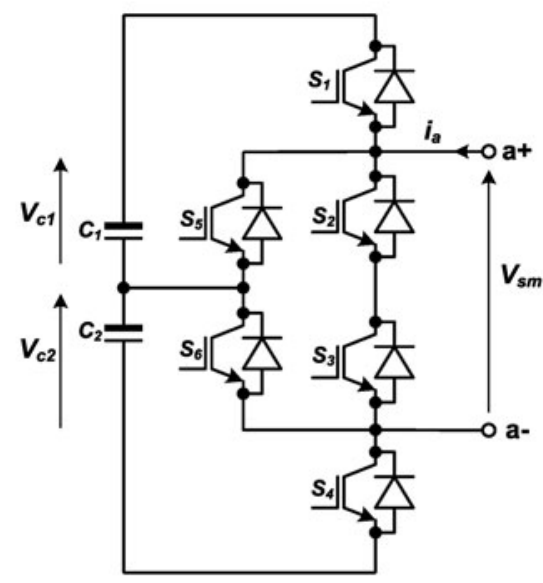

(b)

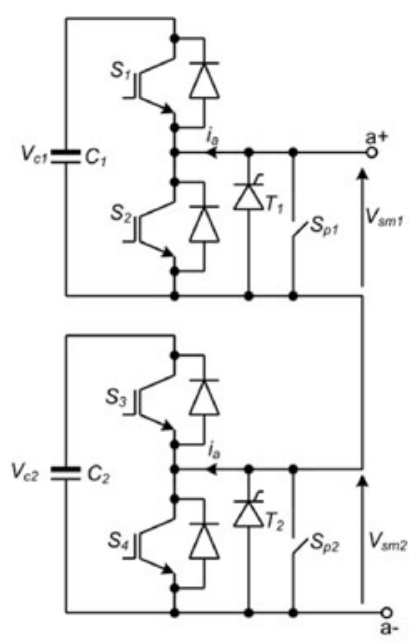

(c)

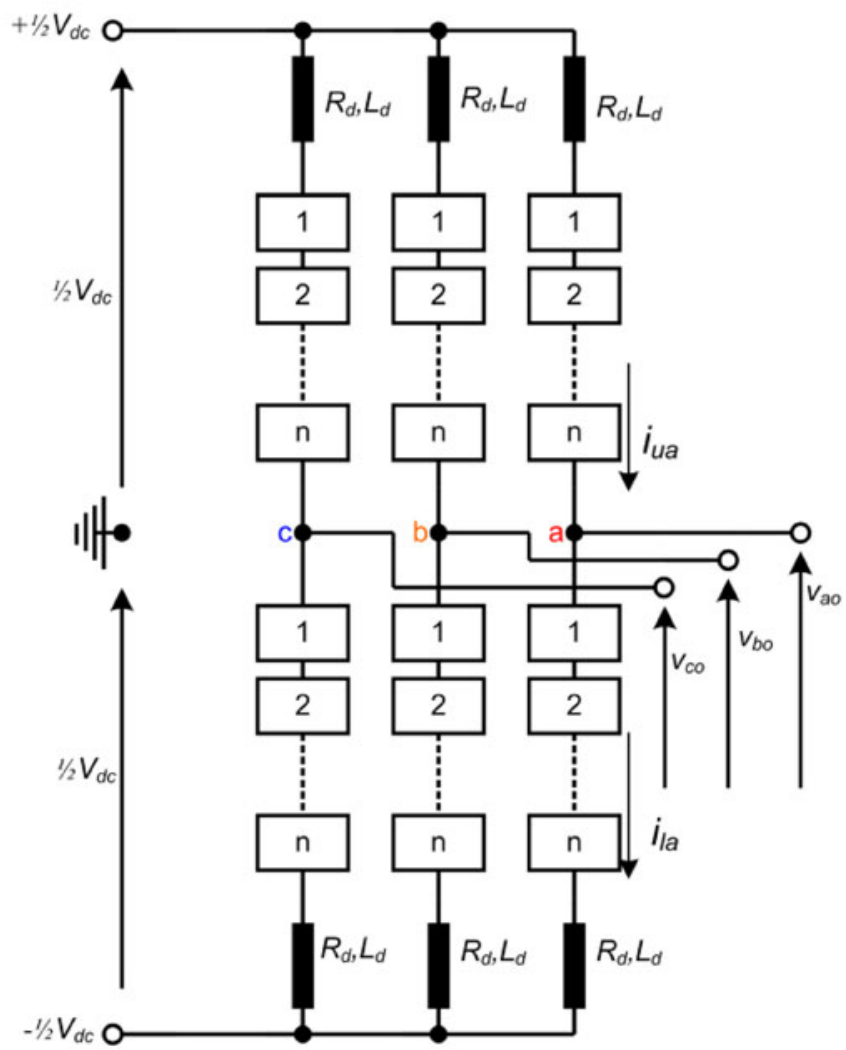

(d)

Fig. 3. (a) and (b) represent type-1 and -2 cell arrangements for MMC in (d), and (c) represents conventional HB cell connection.

to a significant compromise of the power circuit modularity nor its internal fault management (which is necessary for continued operation when limited number of cells fail).

Fig. 1(b) and (i) shows symmetrical bipolar cells that insert two and four semiconductor switches in conduction path during normal operation and generate three and five voltage levels $\left(V_{c}, 0\right.$, and $\left.-V_{c}\right)$ and $\left(2 V_{c}, V_{c}, 0,-V_{c}\right.$, and $\left.-2 V_{c}\right)$, respectively. These symmetrical bipolar cells permit the voltages across MMC upper and lower arms to be modulated between
$V_{\mathrm{dc} 0}$ and 0 , and 0 and $-V_{\mathrm{dc} 0}$ during normal operation with rated positive and negative dc-link voltage, and between $1 / 2 V_{\mathrm{dc} 0}$ and $-1 / 2 V_{\mathrm{dc} 0}$ during operation with zero dc-link voltage [see Fig. 2(a) and (d)]. Such operational flexibility allows MMCs that employ symmetrical bipolar cells to generate peak output phase voltage $V_{m}>1 / 2 m_{\max } V_{\mathrm{dc} 0}$ (overmodulation), without reappearance of the low-order harmonics in the baseband as in traditional voltage source converters, where $m_{\max }$ represents the maximum modulation index. The aforesaid attributes allow 
TABLE I

Summary of Switch States of the Submodule ARRangement IN FIG. 3(b)

\begin{tabular}{|c|c|c|c|c|}
\hline \multirow[t]{2}{*}{ Voltage levels } & \multicolumn{2}{|c|}{ Switching states } & \multirow[t]{2}{*}{ current polarity } & \multirow[t]{2}{*}{ Impact on capacitors } \\
\hline & ON & OFF & & \\
\hline 0 & $S_{2}, S_{3}, S_{5}, S_{6}$ & $S_{1}$ and $S_{4}$ & $\begin{array}{l}i_{a}>0 \\
i_{a}<0\end{array}$ & $C_{1} \rightarrow C_{2} \rightarrow$ \\
\hline$V c$ & $\begin{array}{l}S_{4}, S_{5} \\
S_{1}, S_{6}\end{array}$ & $\begin{array}{l}S_{1}, S_{2}, S_{3}, S_{6} \\
S_{2}, S_{3}, S_{4}, S_{5}\end{array}$ & $\begin{aligned} i_{a} & >0 \\
i_{a} & <0 \\
i_{a} & >0 \\
i_{a} & <0\end{aligned}$ & $\begin{array}{l}C_{1} \rightarrow C_{2} \uparrow \\
C_{1} \rightarrow C_{2} \downarrow \\
C_{1} \uparrow C_{2} \rightarrow \\
C_{1} \downarrow C_{2} \rightarrow\end{array}$ \\
\hline $2 V c$ & $S_{1}, S_{4}$ & $S_{2}, S_{3}, S_{5}, S_{6}$ & $\begin{array}{l}i_{a}>0 \\
i_{a}<0\end{array}$ & $\begin{array}{l}C_{1} \uparrow C_{2} \uparrow \\
C_{1} \downarrow C_{2} \downarrow\end{array}$ \\
\hline
\end{tabular}

Switches $S_{1}-S_{6}$ represent composite switching devices that comprise of IGBT plus antiparallel diodes, and $\rightarrow, \uparrow$, and $\downarrow$ stand for states of charge of the cell capacitors (unchanged, charge, and discharge) for different arm current polarity.

MMCs that use symmetrical bipolar cells to have the largest control range [see Fig. 2(d)], tolerance to dc faults, and bipolar dc-link voltage operation. But these attributes are achieved at the expense of increased semiconductor losses compared to their counterparts that employ unipolar and asymmetrical bipolar cells [5], [13], [14].

Fig. 1(h) shows an example of three-level unipolar cell that offers a dc-fault reverse blocking capability, while it remains subject to many of the aforesaid limitations of the unipolar cells such as operation with the unipolar dc-link voltage. Additionally, it has higher semiconductor losses compared to its counterparts in Fig. 1(c)-(e) because it inserts three semiconductor switches into conduction path compared to two in FC and T-type cells.

The authors in [15] proposed a new type of symmetrical bipolar cell that can generate seven voltage levels to be used in modular ac/ac and dc/ac converters. The modular converter that uses the proposed cell can generate more voltage levels per phase using reduced number of switching devices compared to full-bridge MMCs; thus, the proposed cell is expected to be attractive for applications that demand high-quality output voltage and current waveforms. Additionally, the operating envelope of the MMC that uses the proposed cell is expected to be similar to that of the full-bridge MMC, including operation with positive and negative dc-link voltage and dc-fault reverse blocking. The proposed cell inserts two fewer IGBTs in the conduction path compared to the equivalent full-bridge cells; hence, its semiconductor losses are expected to be lower than the full-bridge cell. The main limitations of the proposed cell are lack of modularity as the rated voltage of the upper capacitor is three times that of the lower capacitor, and rated voltage of the middle switch devices is twice that of the upper and lower switches.

In recent years, several methods have emerged that can be used to control MMCs, with some methods offering maximum control range and flexibility [12], [16], [17]. Some of the popular methods to control half-bridge (HB) modular converter is the standard decoupled current controller in synchronous reference frame that rotates at fundamental frequency $(\omega)$, with a dedicated supplementary controller for suppression of the second-order harmonic current in the phase variables or the synchronous reference frame at twice the fundamental frequency
[7], [13], [18]-[20]. In this control method, the controller that suppresses the second-order harmonic current in each MMC phase leg injects the necessary harmonics into modulation functions of the upper and lower arms in order to suppress the parasitic component of the common-mode current (both ac and dc components of modulation functions are modified). Although this control approach is relatively slow and cell capacitor voltages are highly coupled to dc-link voltage, its ability to suppress second-order harmonic current in converter arms to virtually zero makes it well suited for high-voltage direct-current (HVDC) applications, where converter semiconductor losses (on-state and switching) are paramount.

An improved version of the method is discussed in [7], [13], and [18]-[20], which includes two additional cascaded control loops that regulate the average cell capacitor voltage per phase leg and common-mode current [21]-[23]. This control method could be used with MMCs that employ half- or full-bridge cells and other symmetrical and asymmetrical bipolar cells in Fig. 1 in order to decouple the control of cell capacitor voltages from the dc-link voltage. In this manner, active and reactive powers could be controlled independent of the dc-link voltage in asymmetrical and symmetrical bipolar cells, and over a limited range in unipolar cells such as the HB cell. The main shortcoming of this control method when it is used with $\mathrm{HB}$ and other unipolar cells is that the MMC arms experience relatively high currents during reduced dc-link voltage operation, should the cell capacitor voltages to be controlled independent of the dc-link voltage (fixed at nominal dc-link voltage $V_{\mathrm{dc} 0}$ ).

The authors in [24]-[31] presented several control methods for half- and full-bridge modular converters that employ phaseshifted carriers pulse width modulation. The refined version of this control method is presented in [26], which includes a number of dedicated controllers for common-mode voltage per phase (average capacitor voltage per phase leg), upper and lower arm voltage balancing, and individual cell capacitor voltage balancing (these controllers ensure vertical balancing); controller that ensures the dc-link current is evenly distributed between the phase leg (the average common-mode current in each phase leg must be equal to one-third of the dc-link current, and this controller is for ensuring horizontal balancing). Additionally, basic converter controllers such as dc-link voltage and active and 


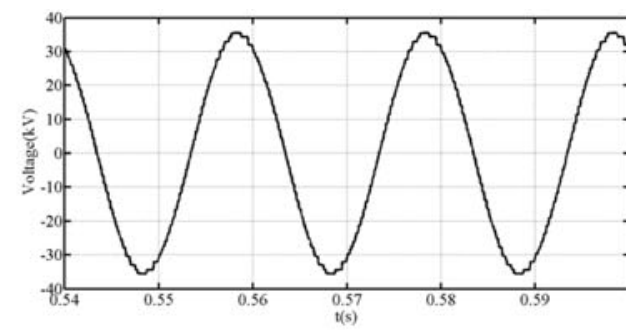

(a)

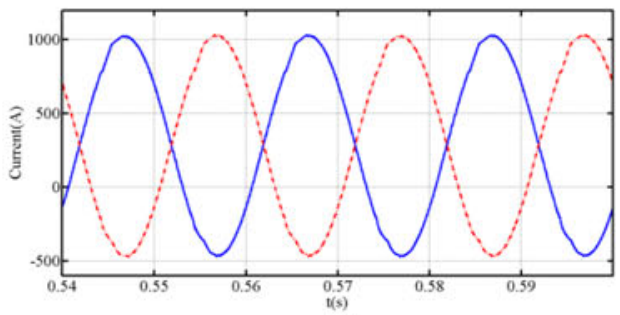

(c)

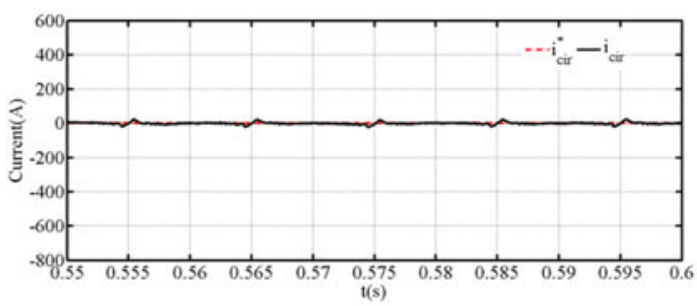

(e)

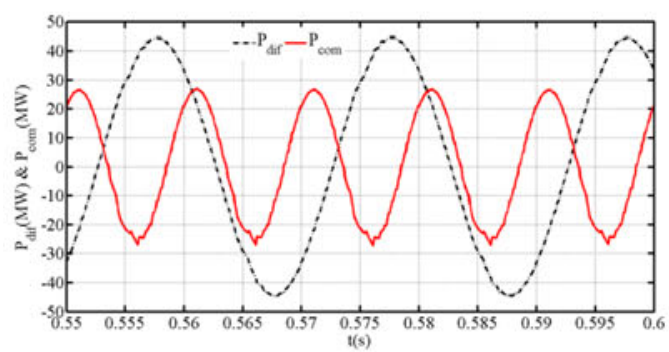

(g)

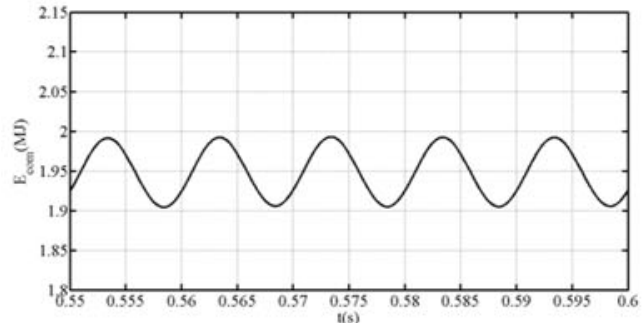

(i)

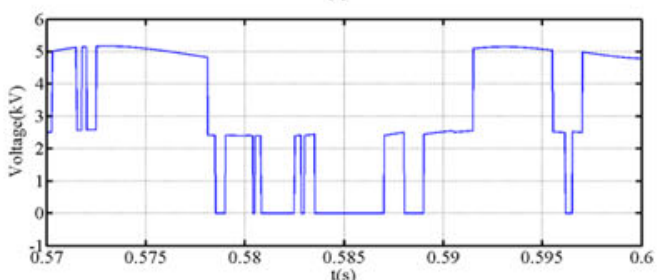

(k)

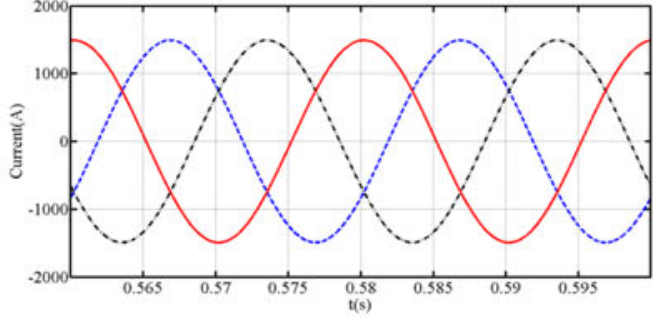

(b)

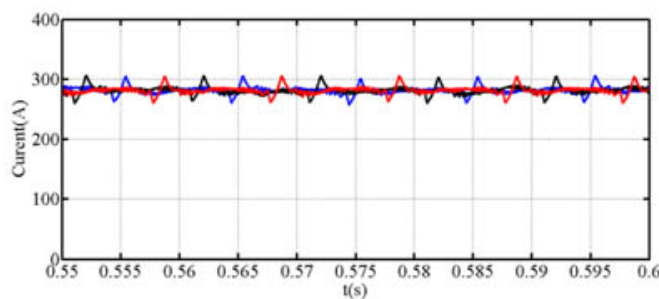

(d)

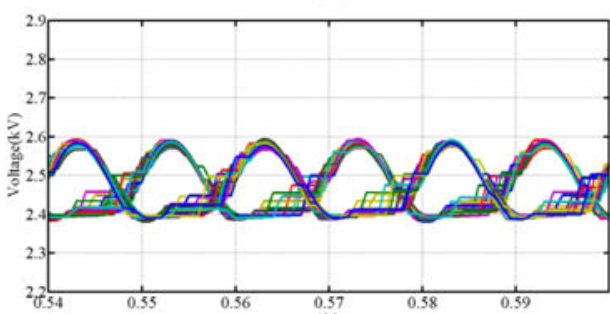

(f)

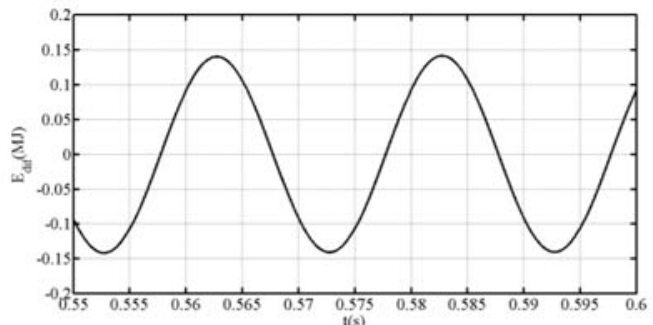

(h)

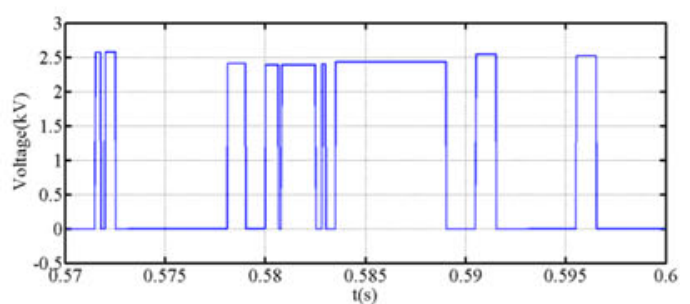

(j)

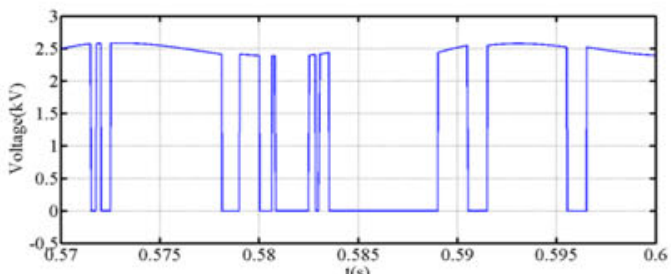

(1)

Fig. 4. Simulation waveforms for the MMC that employs the proposed cell in Fig. 3(b). (a) Phase voltage ( $v_{\text {ao }}$ ). (b) Three-phase output currents. (c) Phase " $a$ "

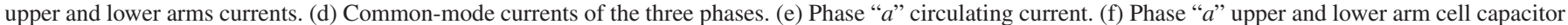
voltages. (g) Phase " $a$ " differential- and common-mode ac powers. (h) Phase " $a$ " differential-mode energy. (i) Phase " $a$ " common-mode energy. (j) Voltage across switch $S_{\mathrm{a} 1}$. (k)Voltage across the composite switch $\left(S_{\mathrm{a} 2}\right.$ and $\left.S_{\mathrm{a} 3}\right)$. (1) Voltage across switch $S_{\mathrm{a} 5}$. 
reactive powers could be included. The main attributes of this control approach are the following: fixed switching frequency per device, independent of operating condition (this makes thermal management and heatsink design simpler), and no need for time-consuming capacitor voltage sorting (which is extremely useful should MMC adopted in dc transformers, with relatively high fundamental frequency). But increased reliance on the control system at the modulation level may raise concern regarding the reliability of this control method, especially during operation in harsh power system environments.

Several methods for controlling MMCs using energy manipulation have been proposed in [16] and [32]-[34]. For example, the method presented in [16] uses the zero sequence (dc) and negative sequence (second-order harmonic current) components of the common-mode current of each phase leg to regulate the total energy stored per converter to be constant and to suppress the cell capacitor energy fluctuations to virtually zero in an attempt to drastically reduce capacitor voltage ripple. While the positive sequence of the common-mode current at fundamental frequency is used to ensure energy balance between the upper and lower arms of each phase leg. Although this approach is interesting, the choice of capacitor voltage ripple instead of the suppression of the second-order harmonic currents in MMC arms is not appropriate for HVDC applications, where the semiconductor losses supersede the capacitor voltage ripple, especially as all the above control methods are able to keep the capacitor voltage ripples well within the tolerable limits. Additionally, the use of arm energy balancing in the practical MMC (where the cell capacitances may have large tolerances) may lead to substantial voltage difference between upper and lower arms of the same phase leg, thus leading to appearance of even harmonic voltages and currents in the baseband.

This paper presents a new cell arrangement that can reduce MMC semiconductor losses beyond that of the HB-MMC, eliminate the need for the protective thyristor used in HB-MMC to deviate part of the fault current from the freewheeling diodes of the main switches that bypass the cell capacitors when the converter is blocked during dc fault, and facilitate continued operation of the MMC during internal cell failure, without the need for mechanical bypass switches. The viability of the proposed cell is demonstrated using simulations and experimentations. In these demonstrations, a switching model of the MMC with 16 cells and 32 capacitors per arm is used to illustrate device (modulation, capacitor voltage balancing, and semiconductor losses) and system aspects (pole-to-pole dc short circuit, unbalanced operation, and internal fault management), and two prototypes of the single-phase MMC with HB and proposed cells for loss and performance comparison. It has been shown that the proposed MMC is promising as it has lower semiconductor loss compared to HB-MMC, and its unique cell structure enables dc short-circuit survival over an extended period, without the need for protective thyristor as in the HB-MMC.

\section{PROPOSED MMC}

Fig. 3 presents two types of cells that can be used in MMCs to reduce the number of isolated dc/dc converters required to supply the driving circuits of the semiconductor switches. Fig. 3(a)
TABLE II

Detailed Current Path of the Proposed Submodule in Fig. 3(b)

\begin{tabular}{lccc}
\hline \hline Voltage levels & Conduction path & Switch states & current polarity \\
\hline 0 & $T_{2}, T_{3}, T_{5}, T_{6}$ & $S_{2}, S_{3}, S_{5}, S 6$ & $i_{a}>0$ \\
& $D_{2}, D_{3}, D_{5}, D_{6}$ & & $i_{a}<0$ \\
$V_{c}$ & $D_{4} T_{5}$ & $S_{4} S_{5}$ & $i_{a}>0$ \\
& $T_{4} D_{5}$ & & $i_{a}<0$ \\
& $D_{1} T_{6}$ & $S_{1} S_{6}$ & $i_{a}>0$ \\
& $T_{1} D_{6}$ & & $i_{a}<0$ \\
$2 V_{c}$ & $D_{1}, D_{4}$ & $S_{1} S_{4}$ & $i_{a}>0$ \\
& $T_{1}, T_{4}$ & & $i_{a}<0$ \\
\hline \hline
\end{tabular}

shows a basic cell arrangement that is formed by back-to-back connection of two versions of the HB cells, and it can generate three voltage levels between " $a+$ " and " $a-$, , $V_{\mathrm{sm}}=$ " 0 ,", " $V_{c}$ ", and " $2 V_{c}$ " should both cell capacitor voltages $V_{c 1}$ and $V_{c 2}$ be regulated at $V_{c}$. In this cell arrangement, the voltage level " $V_{c}$ ", represents the redundant switch state that can be generated by two switch combinations and can be used in conjunction with the arm current polarity to balance the cell capacitor voltages globally or locally at the cell level. This approach can be extended to the MMC with hundreds of cells per arm, where " $n$ " cells in each MMC arm could be divided into " $m$ " subgroups, with each subgroup consisting of " $r$ " cells and capable of generating " $r+1$ " voltage levels, and $\{n, m, r\} \in \mathbb{N}$ and $n=m \times r$.

Apart from the aforesaid attributes, an MMC that uses the cells in Fig. 3(a) has the same number of cell capacitors, switching devices in conduction path and loss distribution as in conventional HB cells in Fig. 3(c), including the efficiency. Fig. 3(b) presents an alternative submodule arrangement that inherits all the attributes of the cell arrangement in Fig. 3(a) and offers new set of features such as reduced semiconductors losses and improved utilization of semiconductor switches. Table I summarizes the switch states of the submodules in Fig. 3(b). Voltage level " $V_{c}$ " offers redundant switch states that can be exploited to balance capacitors $C_{1}$ and $C_{2}$ within each submodule at the cell level, without increasing capacitor voltage ripple. Notice that a zero-voltage level, which is used to bypass the cell capacitors $C_{1}$ and $C_{2}$, could be achieved by turning ON switches $S_{2}, S_{3}, S_{5}$, and $S_{6}$ simultaneously. This leads to distribution of the arm current " $i_{a}$ " between two parallel paths, $S_{2} S_{3}$ and $S_{5} S_{6}$, each carrying half of the arm current $\left(\frac{1}{2} i_{a}\right)$, thus leading to reduced conduction loss per cell compared to conventional HB cell. Additionally, the protective thyristor "T" being used to deviate part of the dc-fault current from the freewheeling diodes of the switches $S_{2}$ and $S_{3}$ in conventional HB cell in Fig. 3(c) or in the cell arrangement in Fig. 3(a) is no longer required, because the freewheeling diodes of switches $S_{2} S_{3}$ and $S_{5} S_{6}$ will be sufficient to handle dc-fault current over extended period of time. Also, the mechanical bypass switch in each HB cell in Fig. 3(c) could be eliminated as the semiconductor switches $S_{2}$ and $S_{3}$ could be used to bypass the damaged cell.

When the cell arrangement in Fig. 3(b) is used in a generic MMC in Fig. 3(d), its modulation and control remain the same as in HB-MMC case. Therefore, for phase " $a$," the upper and lower arm modulation functions are: $\gamma_{a 1}=\frac{1}{2}\left[\alpha_{d}-m_{a} \sin (\omega t+\delta)\right]$ 


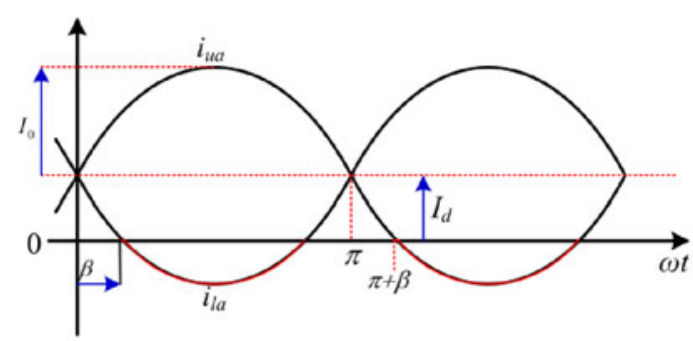

(a)

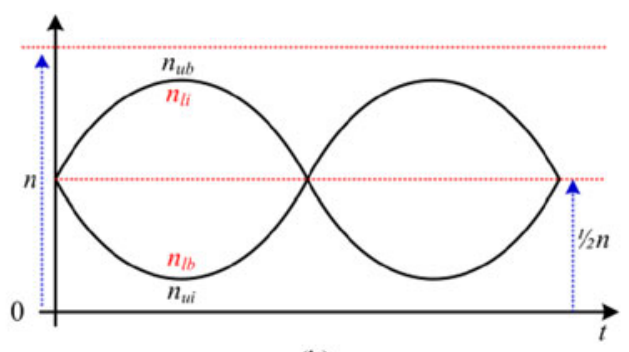

(b)

Fig. 5. (a) and (b) MMC upper and lower arm currents $\left(i_{u}\right.$ and $\left.i_{l}\right)$ and their corresponding insertion functions.

TABLE III

VALIDATION OF ANALYTICAL ESTIMATED ON-STATE LOSS Against THAT ObTained Using Simulation (MMC With THE PRoposed CELL ARRANGEMENT VERSUS THAT USES HB CELL)

\begin{tabular}{lcccc}
\hline \hline MMC & $\cos \varphi=1$ & $\cos \varphi=0.8$ & $\cos \varphi=0$ & \\
\hline Proposed cell & $4.99 \mathrm{MW}$ & $4.72 \mathrm{MW}$ & $4.27 \mathrm{MW}$ & Analytical \\
& $4.7 \mathrm{MW}$ & $4.50 \mathrm{MW}$ & 4.01 & Simulation \\
Half-bridge cell & $5.59 \mathrm{MW}$ & $5.25 \mathrm{MW}$ & $4.68 \mathrm{MW}$ & Analytical \\
& $5.51 \mathrm{MW}$ & $5.00 \mathrm{MW}$ & $4.50 \mathrm{MW}$ & Simulation \\
\hline \hline
\end{tabular}

and $\gamma_{a 2}=\frac{1}{2}\left[\alpha_{d}+m_{a} \sin (\omega t+\delta)\right]$, where dc modulation index $\alpha_{d}=V_{\mathrm{dc}} / \bar{V}_{c} \approx 1$ during normal operation, ac modulation index $m_{a}=V_{m} / \frac{1}{2} \bar{V}_{c}\left(V_{m}\right.$ and $V_{\mathrm{dc}}$ are peak phase and pole-to-pole dc voltages), and $\bar{V}_{c}$ represents the average voltage across cell capacitors of each arm.

Amplitude modulation and cell capacitor voltage balancing of the MMC that uses the submodule in Fig. 3(b) can be performed using one of the following methods.

\section{A. Method I}

This method is summarized as follows.

1) All cell capacitor voltages are indexed as $V_{\text {cij }}$, where " $i$ " identifies the location of individual cell in each $\operatorname{arm}(i \in \mathbb{N}$ and it varies from 1 to $n$ ), and " $j$ " points to the location of individual capacitor within each submodule $(j \in \mathbb{N}$ and it varies from 1 to 2 ).

2) Marquardt's capacitor voltage balancing method that sorts the capacitor voltages of each arm in ascending or descending order could be applied to select the number of cell capacitors to be switched in and out the power path, taking into account the voltage level to be synthesized in each sampling period, cell capacitor voltage magnitudes, and arm current polarities. Insertion functions that determine the number of submodules to be inserted and bypassed from the upper and lower arms for phase " $a$ " are $n_{\mathrm{ui}}=n \times \gamma_{a 1}$ and $n_{\mathrm{ub}}=n-n_{\mathrm{ui}}$, and $n_{\mathrm{li}}=n \times \gamma_{a 2}$ and $n_{\mathrm{lb}}=n-n_{\mathrm{li}}$, respectively (where $n$ stands for the number of cell capacitors per arm).

3) Since the precise locations of the submodule capacitors to be inserted into power path and that to be bypassed are known from step 2, the mapping summarized in Table I can be directly used to generate the gating signals for
TABLE IV

SuMmary of Estimated Switching LosSES of Both MMCs (SimUlation)

\begin{tabular}{llll}
\hline \hline & $\cos \varphi=1$ & $\cos \varphi=0.8$ & $\cos \varphi=0$ \\
\hline Proposed cell & $2.30 \mathrm{MW}$ & $2.18 \mathrm{MW}$ & $\begin{array}{l}2.99 \mathrm{MW} \\
3.75 \mathrm{MW}\end{array}$ \\
Half-bridge cell & $3.39 \mathrm{MW}$ & $3.11 \mathrm{MW}$ & \\
\hline \hline
\end{tabular}

TABLE V

Summary of Total SEmiconductor Losses (ON-STATE Plus Switching) CONVERTER OF THE PROPOSED MMC AGAINST HB MMC

\begin{tabular}{lccc}
\hline \hline & $\cos \varphi=1$ & $\cos \varphi=0.8$ & $\cos \varphi=0$ \\
\hline Proposed cell & $7.29 \mathrm{MW}(0.69 \%)$ & $6.90 \mathrm{MW}(0.66 \%)$ & $7.26 \mathrm{MW}(0.69 \%)$ \\
Half-bridge cell & $8.98 \mathrm{MW}(0.85 \%)$ & $8.36 \mathrm{MW}(0.80 \%)$ & $8.05 \mathrm{MW}(0.77 \%)$ \\
Cost saving & $152.1 \mathrm{M} €$ & $131.4 \mathrm{M} €$ & $71.1 \mathrm{M} €$ \\
\hline \hline
\end{tabular}

individual switches $S_{\mathrm{ik}}$, where " $k$ " varies from 1 to 6 and $k \in \mathbb{N}$.

\section{B. Method II}

This method is summarized as follows.

1) Vector $\left(\boldsymbol{V}_{c}\right)$ of capacitor voltages of each arm is created.

2) Submodule capacitors to be inserted into power path from each arm are determined using sorting of the capacitor voltages $\left[\boldsymbol{A}_{1} \boldsymbol{I} \boldsymbol{X}\right]=\operatorname{sort}\left(\boldsymbol{V}_{c}\right.$, "ascend") and $\left[\boldsymbol{B}_{1} \boldsymbol{I} \boldsymbol{Y}\right]=$ sort ( $\boldsymbol{V}_{c}$, "descend"), where $I X$ and $I Y$ are index vectors that hold locations of the cells to be switched in and out of the power path, and $\boldsymbol{A}_{1}$ and $\boldsymbol{B}_{1}$ are sorted versions of the cell capacitor voltages $\boldsymbol{V}_{c}$ in ascending and descending orders. A vector of status signals $\lambda[i]=1$ and 0 is assigned to the submodule capacitors to be inserted into the power path and those to be bypassed, taking into account the arm current polarity and voltage level to be synthesized (where " $i$ " is a positive integer that varies from 1 to $n$ ).

3) The status vector $\lambda$ that was created in step 2 will be used to determine the number of capacitors to be inserted into power path from each submodule using $\sigma[k]=\lambda_{1}[k]+$ $\lambda_{2}[k]$, where $\lambda_{1}[k]=\lambda[2 k-1]$ and $\lambda_{2}[k]=\lambda[2 k], k$ is a positive integer that varies from 1 to $1 / 2 n$, and $\lambda_{1}$ and $\lambda_{2}$ are vectors that represent status of the capacitors $C_{1 k}$ and $C_{2 k}$. Notice that $\sigma[k]=0,1$ and 2 stand for the 


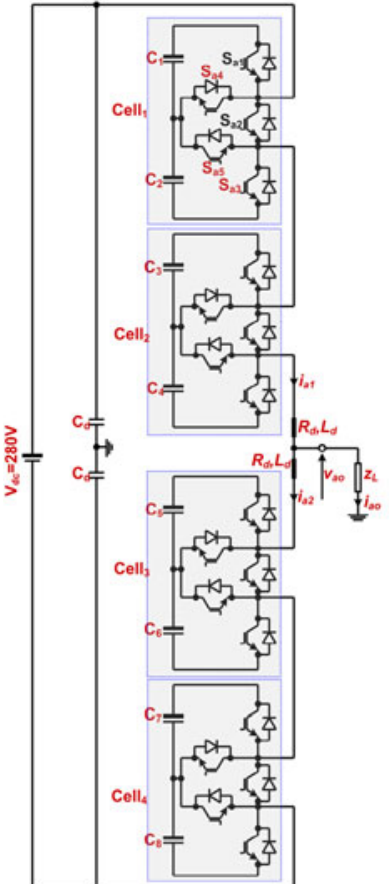

(a)

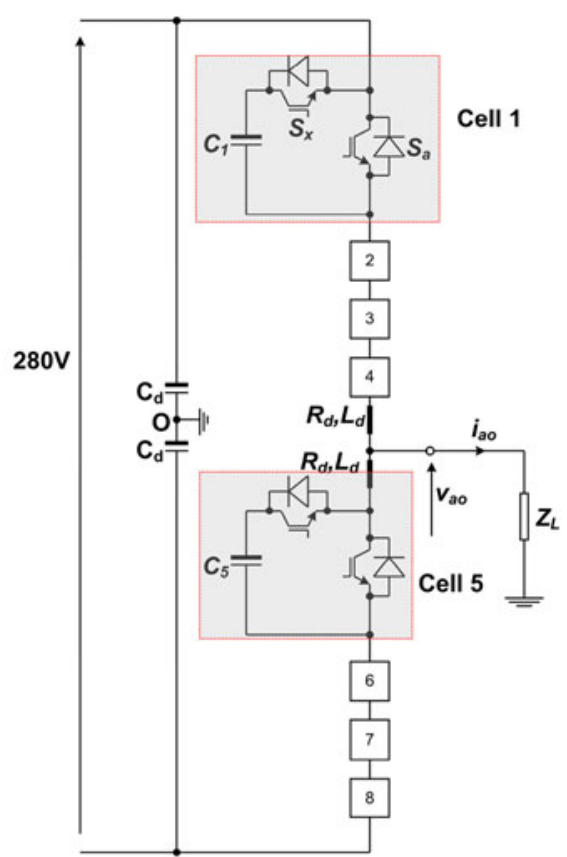

(b)

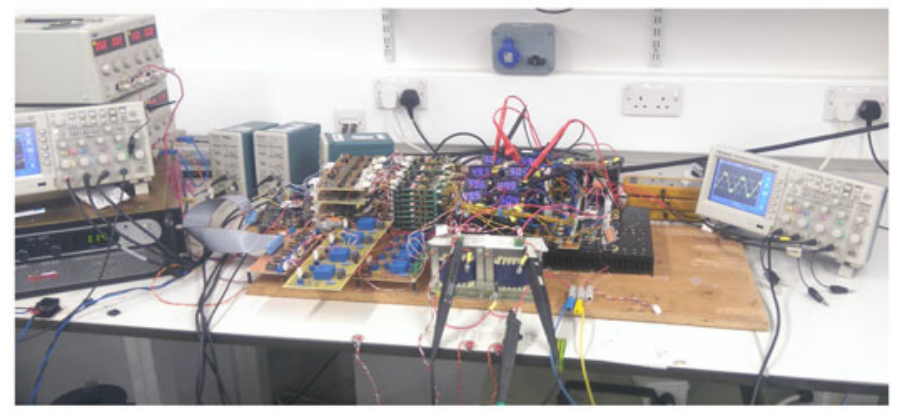

(c)

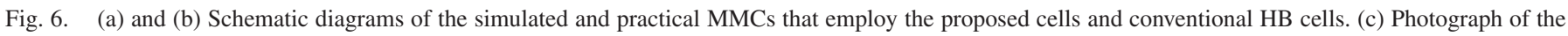
prototypes of both MMCs.

following cases: when both capacitors of $k$ th submodule are bypassed, one of the submodule capacitors is inserted into the power path and the other is bypassed, and both capacitors of $k$ th submodule are inserted into the power path.

4) Using information provided by vector $\sigma$ and mapping in Table I, the gating signals of individual switches are generated and voltages across the cell capacitors $C_{1 k}$ and $C_{2 k}$ of each $k$ th submodule are balanced locally, taking into account arm current polarity.

Notice that in method I, the cell capacitor voltage balancing in step 2 is performed in a similar manner as that in conventional HB-MMC, while in method II, the cell capacitor voltage balancing is performed at cell level, which is simpler and faster. A flowchart that depicts implementation steps of method II is provided in the Appendix (see Fig. 14).

Fig. 4 shows basic waveforms of a three-phase MMC that employs 16 of the proposed cells in Fig. 3(b) in its arms, being controlled using amplitude modulation and the cell capacitor voltage balancing method II. The following parameters are assumed in this illustration: $V_{\mathrm{dc}}=80 \mathrm{kV}, C_{m}=10 \mathrm{mH}$, the number of cells per arm is 16 (two capacitors per cell), arm reactor inductance and internal resistance are $L_{\mathrm{d}}=10 \mathrm{mH}$ and $R_{\mathrm{d}}=0.25 \Omega$, load resistance and inductance are $20 \Omega$ and $40 \mathrm{mH}$ (equivalent to three-phase power of 66.8 $\mathrm{MW}$ and 42.1 MVAr), and 0.90 modulation index. In this example, the second-harmonic current component of the common mode in each phase is suppressed using a resonant controller. The plots for the prefilter output phase voltage, three-phase output currents, phase " $a$ " upper and lower arm currents and phase " $a$ " cell capacitor voltages in Fig. 4(a)-(c) and (f) show that the MMC that uses the proposed cell operates satisfactorily, retains seamless current commutation between upper and lower arms as with the HB-MMC, and the voltages across the cell capacitors are well regulated around $1 / 2 V_{\mathrm{dc}} / n\left({ }^{1}\right.$ text $\left./ 2 \times 80 / 16 \approx 2.5 \mathrm{kV}\right)$. Fig. 4(d) and (e) shows that phase " $a$ " common-mode current is practically dc, with its parasitic component (second-harmonic current) being successfully suppressed to nearly zero. Fig. 4(g) 
shows the common- and differential-mode ac powers the upper and lower arm cell capacitors of phase " $a$ " exchange with the dc and ac sides. Observe that the common- and differential-mode ac powers oscillate at second-harmonic and fundamental frequencies and adhere to the following analytical expressions: $p_{\text {com }}(t)=p_{\text {ac } 1}(t)+p_{\text {ac } 2}(t)=1 / 4 m V_{\mathrm{dc}} I_{m} \cos (2 \omega t+\varphi)=$ $1 / 3 P \cos 2 \omega \mathrm{t}-1 / 3 \mathrm{Q} \sin 2 \omega \mathrm{t}$ and $p_{\mathrm{dif}}(t)=p_{\mathrm{ac} 1}(t)-p_{\mathrm{ac} 2}(t)=$ ${ }_{1 / 3} P(2-m) / m d \times \sin \omega t-2 / 3 \mathrm{Q} / \mathrm{m} \times \cos \omega \mathrm{t}$, which are identical to that of the HB-MMC, where $p_{\mathrm{ac} 1}=v_{a 1} i_{a 1}$ and $p_{\text {ac2 }}=v_{a 2} i_{a 2}$, and $P$ and $Q$ are the average active and reactive powers the converter exchanges with the ac side or load. The absence of dc components in both ac power components confirms that the upper and lower arm cell capacitors exchange zero average active power with the dc and dc sides; thus, natural balancing of the cell capacitor voltages could be ensured with simple cell rotation as suggested originally [35].

The differential- and common-mode energies displayed in Fig. 4(h) and (i) indicate that the converter being studied has constant average common-mode energy and zero average differential-mode energy, and the latter indicates that the energy balance between the upper and lower arm cell capacitors is ensured (vertical balancing). These common- and differentialmode energies are described analytically as follows:

$$
\begin{aligned}
p_{\mathrm{ac} 1}(t)= & v_{a 1} i_{a 1}=\frac{1}{4} I_{m} V_{\mathrm{dc}} \sin (\omega t+\varphi)-\frac{1}{2} m I_{d} V_{\mathrm{dc}} \\
& \times \sin \omega t+\frac{1}{8} m I_{m} V_{\mathrm{dc}} \cos (2 \omega t+\varphi) \\
p_{\mathrm{ac} 2}(t)= & v_{a 2} i_{a 2}=-\frac{1}{4} I_{m} V_{\mathrm{dc}} \sin (\omega t+\varphi)+\frac{1}{2} m I_{d} V_{\mathrm{dc}} \\
& \times \sin \omega t+\frac{1}{8} m I_{m} V_{\mathrm{dc}} \cos (2 \omega t+\varphi) .
\end{aligned}
$$

The upper and lower arm cell capacitors energies are

$$
\begin{aligned}
\frac{d E_{1}(t)}{d t}= & p_{\mathrm{ac} 1}(t) \Rightarrow E_{1}(t)=E_{1}(0)-\frac{1}{4} \frac{I_{m} V_{\mathrm{dc}}}{\omega} \\
& \times \cos (\omega t+\varphi)+\frac{1}{2} \frac{m I_{d} V_{\mathrm{dc}}}{\omega} \\
& \times \cos \omega t+\frac{1}{16} m I_{m} V_{\mathrm{dc}} \sin (2 \omega t+\varphi) \\
\frac{d E_{2}(t)}{d t}= & p_{\mathrm{ac} 2}(t) \Rightarrow E_{2}(t)=E_{2}(0)+\frac{1}{4} \frac{I_{m} V_{\mathrm{dc}}}{\omega} \\
& \times \cos (\omega t+\varphi)-\frac{1}{2} \frac{m I_{d} V_{\mathrm{dc}}}{\omega} \\
& \times \cos \omega t+\frac{1}{16} m I_{m} V_{\mathrm{dc}} \sin (2 \omega t+\varphi)
\end{aligned}
$$

where $\quad E_{1}(0)=E_{2}(0)=E(0) \approx N_{c} \times \frac{1}{2} C_{m}\left[\frac{V_{c}}{N_{c}}\right]^{2}=$ $\frac{1}{2} \frac{C_{m} V_{c}^{2}}{N_{c}}$, and $V_{c} \approx V_{\mathrm{dc}}-2 R_{d} I_{d}-2 N_{c} V_{\text {device }} \quad\left(V_{\text {device }}\right.$ represents dc voltage drop per device).
TABLE VI

SiMULATION AND TEST RIG PARAMETERS

\begin{tabular}{lc}
\hline \hline DC-link voltage $\left(V_{\mathrm{dc}}\right)$ & $280 \mathrm{~V}$ \\
Number of cells (proposed) & 2 \\
Number of cells (half-bridge) & 4 \\
Arm reactor inductance $\left(L_{d}\right)$ & $3 \mathrm{mH}$ \\
Arm reactor internal resistance $\left(R_{d}\right)$ & 0.1 \\
Cell capacitance $\left(C_{m}\right)$ & $2.2 \mathrm{mF}$ \\
Load resistance & $9.5 \Omega$ \\
Load inductance & $6 \mathrm{mH}$ \\
Switching frequency & $2.4 \mathrm{kHz}$ \\
Average voltage per capacitor & $70 \mathrm{~V}$ \\
\hline \hline
\end{tabular}

From (3) and (4), common- and differential-mode energies are

$$
\begin{aligned}
E_{\mathrm{com}}(t) & =\frac{C_{m} V_{c}^{2}}{N_{c}}+\frac{1}{6 \omega}[P \sin 2 \omega t+Q \cos 2 \omega t] \\
E_{\mathrm{dif}}(t) & =\frac{1}{6 \omega}[P(m-1 / m) \cos \omega t+2 Q / m \sin \omega t] .
\end{aligned}
$$

Observe that (5) and (6) agree with the simulation waveforms for the common- and differential-mode energies presented in Fig. 4(h) and (i). Equations (5) and (6) indicate that the commonand differential-mode energies could be manipulated through the second- and first-harmonic currents. While Fig. 4(d) shows the common-mode currents of the three-phase legs have the same magnitude, which indicates that the horizontal balancing or even distribution of dc-link current between the three phases is ensured.

The voltage waveforms across the switching devices $S_{1}, S_{2}$, $S_{3}$, and $S_{5}$ in Fig. 4(j)-(1) indicate that the switching devices of the MMC that employs the proposed cell operate at reduced average switching frequency as in HB-MMC. Since the composite switch $S_{2} S_{3}$ in Fig. 3(b) is exposed to multilevel voltage waveform as in Fig. 4(f) with one voltage level switched at each instant, the composite switch $S_{2} S_{3}$ can be formed without the need for stringent requirement of typical series device connection. The voltage waveforms in Fig. 4(j)-(1) show that the conduction periods of switches $S_{1}$ and $S_{5}$ in the proposed cell are not significantly different as that between the main and auxiliary switches $S_{1}$ and $S_{2}$ of the HB cell [see Fig. 3(b) and (c)], with the composite switch $S_{2} S_{3}$ being used to halve the currents in $S_{5}$ and $S_{6}$ (thus, better loss distribution is expected).

\section{ANALYTICAL SEMICONDUCTOR LOSS ESTIMATION}

Since semiconductor loss is a decisive factor that determines successful adoption or abandonment of the modular-type converters in practical systems, this section presents an approximate method for loss calculations, and this method is used in this paper to compare the semiconductor loss of the MMC that employs the proposed cell against that uses conventional HB cell. Notice that the MMC with HB cell and proposed cell present a fixed number of switching devices in conduction path for a given voltage stress per device and dc-link voltage, irrespective of modulation strategy. For an example, out of " $2 n$ " cell capacitors available for selection in each phase leg at any instant, " $2 n$ " switches must be used to insert " $n$ " cell capacitors 


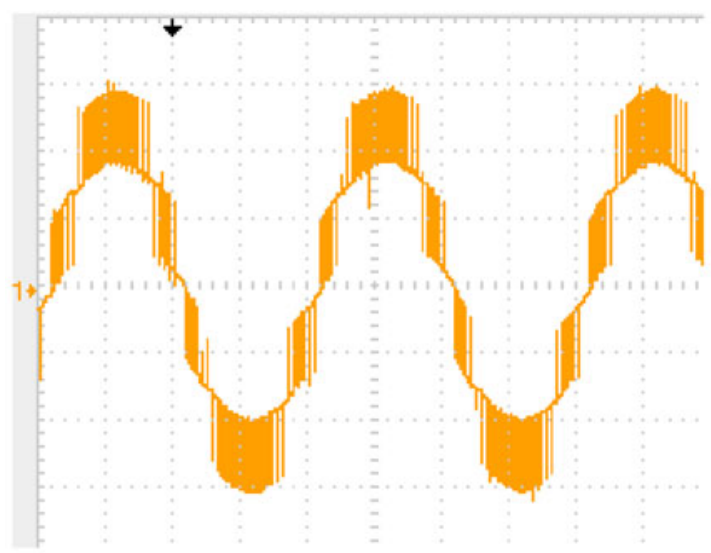

(a)

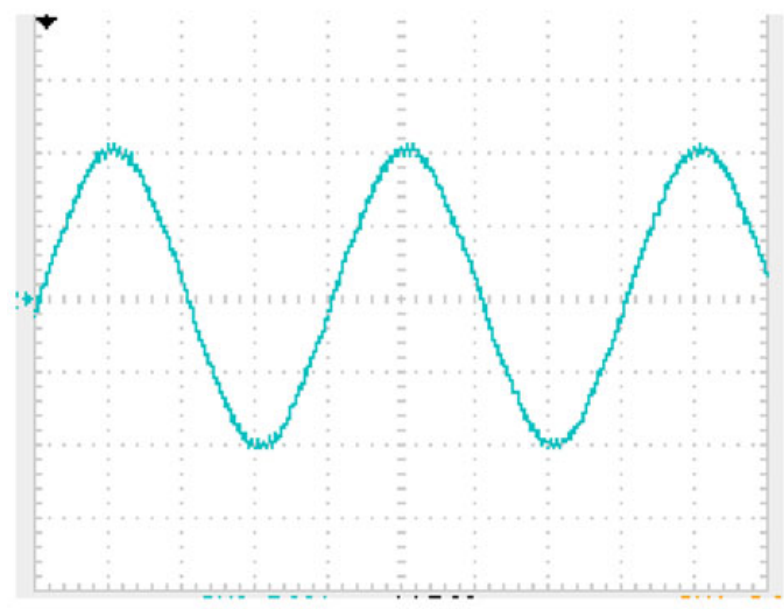

(c)

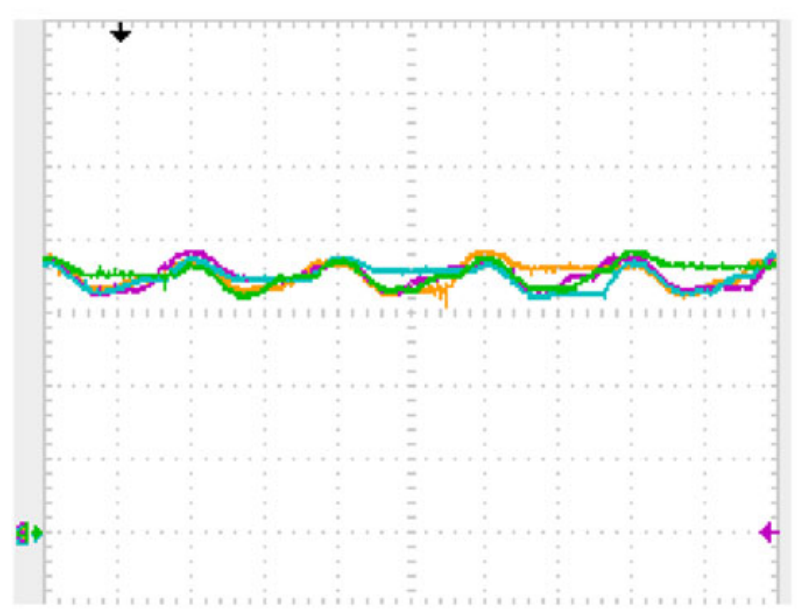

(e)

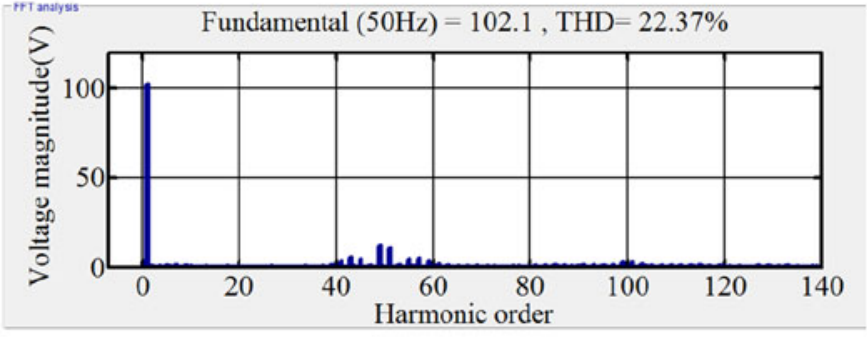

(b)

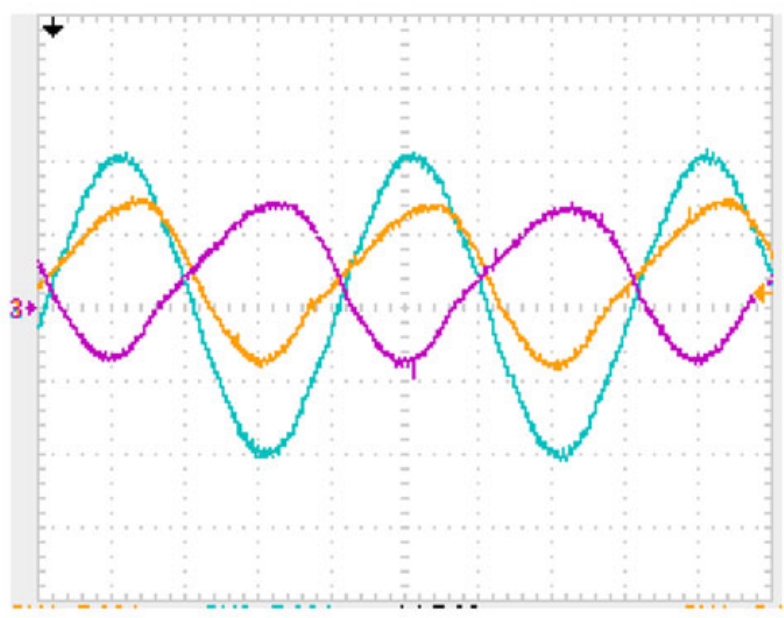

(d)

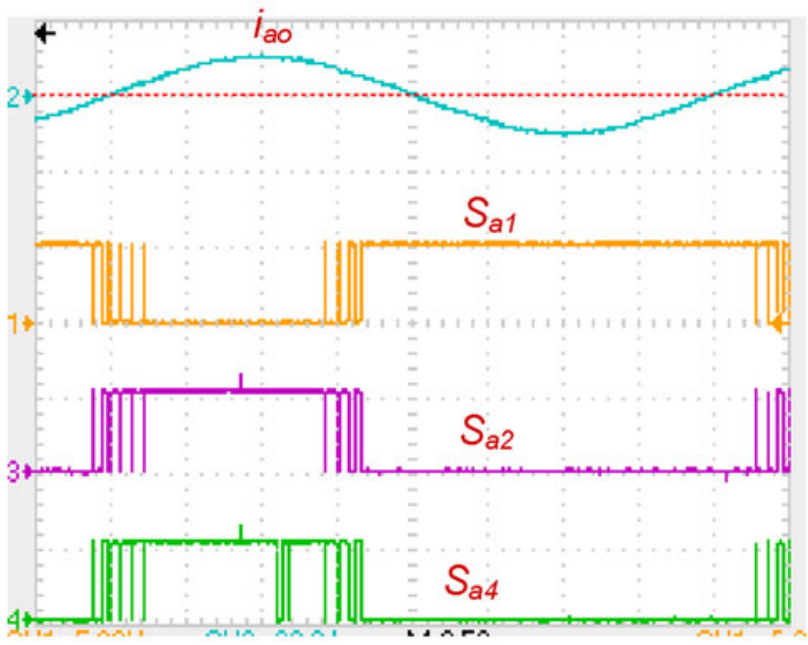

(f)

Fig. 7. Experimental results from scaled down prototype of the MMC with the proposed cell as shown in Fig 6.(a) and (c). (a) Prefilter output voltage (5 ms/div and $40 \mathrm{~V} / \mathrm{div}$ ). (b) Phase voltage spectrum. (c) Output phase current $(5 \mathrm{~ms} / \mathrm{div}$ and $5 \mathrm{~A} / \mathrm{div}$ ). (d) Upper and lower arm current and output phase or load current $(5 \mathrm{~ms} / \mathrm{div}$ and $5 \mathrm{~A} / \mathrm{div})$. (e) Upper arm cell capacitor voltages $(10 \mathrm{~ms} / \mathrm{div}$ and $20 \mathrm{~V} / \mathrm{div})$. (f) Output phase current and samples of gating signals of the one cell during converter operation ( $2.5 \mathrm{~ms} / \mathrm{div}, 5 \mathrm{~V} / \mathrm{div}$ for $S_{\mathrm{a} 1}, S_{\mathrm{a} 2}$, and $S_{\mathrm{a} 4}$ and $20 \mathrm{~A} /$ dive for $i_{\mathrm{ao}}$ ). 


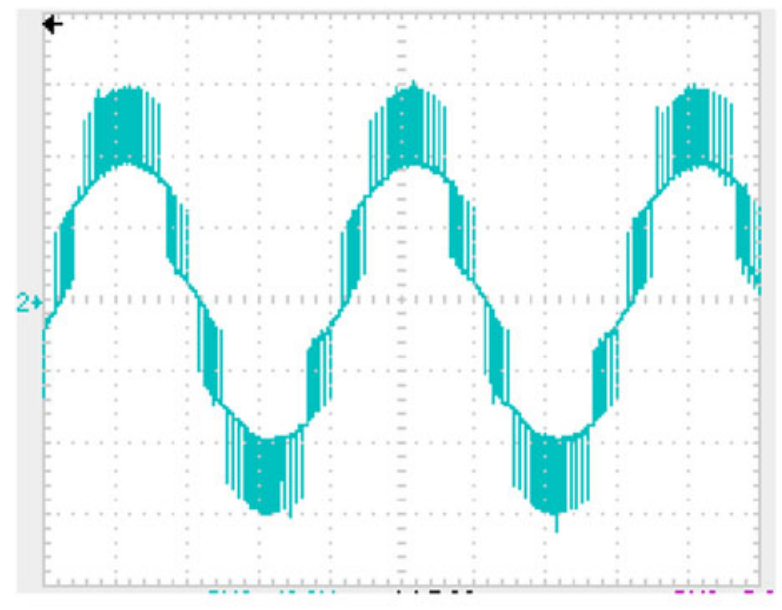

(a)

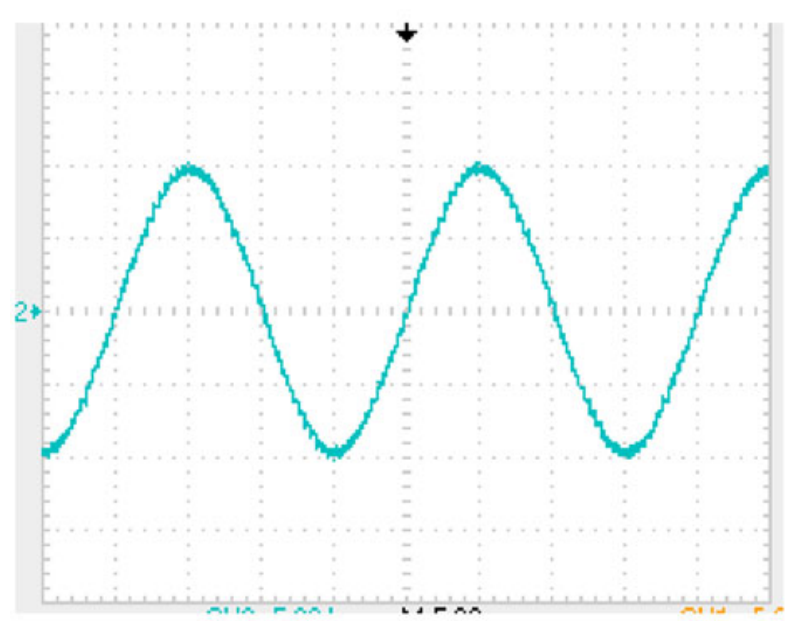

(c)

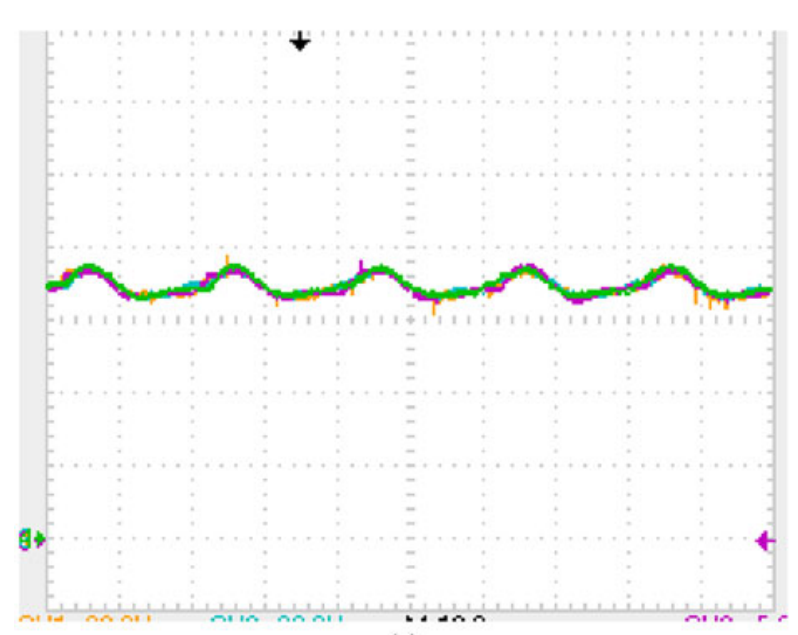

(e)

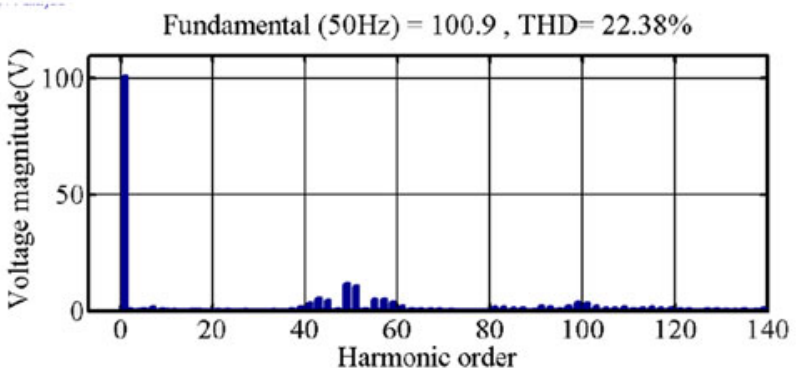

(b)

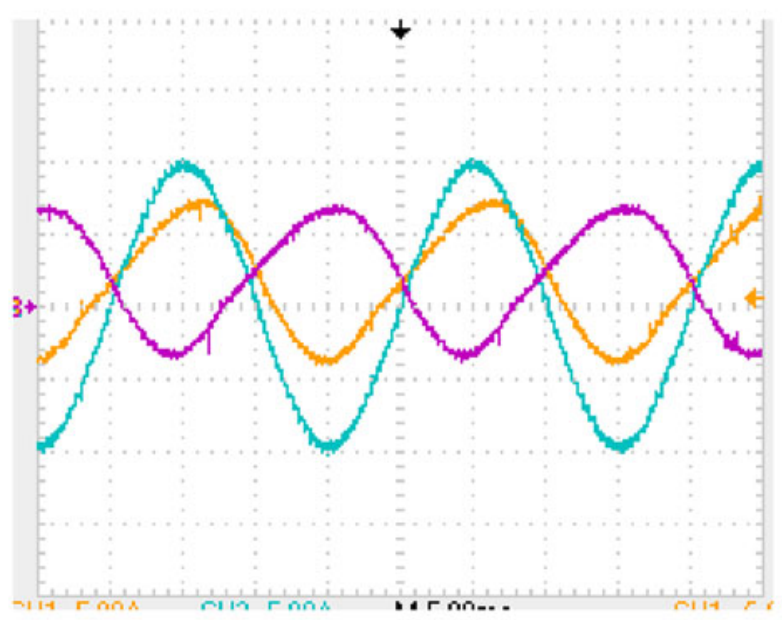

(d)

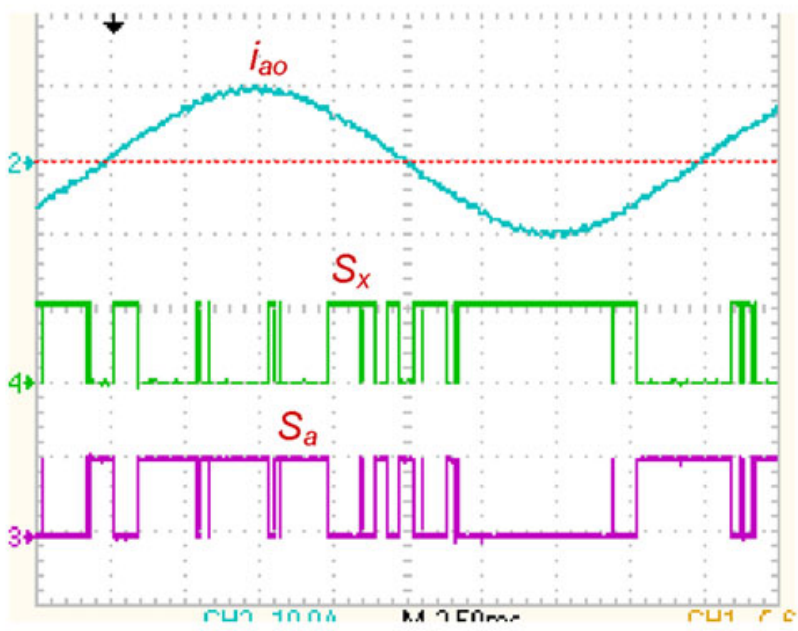

(f)

Fig. 8. Experimental results from scaled down prototype of the MMC with the conventional HB cell as shown in Fig. 6(b) and (c). (a) Prefilter output voltage $(5 \mathrm{~ms} / \mathrm{div}$ and $40 \mathrm{~V} / \mathrm{div})$. (b) Phase voltage spectrum. (c) Output phase current (5 ms/div and $5 \mathrm{~A} / \mathrm{div}$ ). (d) Upper and lower arm current and output phase or load current ( $5 \mathrm{~ms} / \mathrm{div}$ and $5 \mathrm{~A} / \mathrm{div})$. (e) Per arm cell capacitor voltages $(10 \mathrm{~ms} / \mathrm{div}$ and $20 \mathrm{~V} / \mathrm{div})$. (f) Output phase current and samples of gating signals of the one cell during converter operation $\left(2.5 \mathrm{~ms} / \mathrm{div}, 5 \mathrm{~V} / \mathrm{div}\right.$ for $S_{\mathrm{x}}$ and $S_{\mathrm{a}}$ and $10 \mathrm{~A} /$ dive for $\left.i_{\mathrm{ao}}\right)$. 
TABLE VII

SUMMARY OF THE EXPERIMENTAL LOSS

\begin{tabular}{lcc}
\hline \hline & Proposed MMC & HB-MMC \\
\hline Input dc power $\left(P_{\mathrm{dc}}\right)$ & $529.2 \mathrm{~W}$ & $529.2 \mathrm{~W}$ \\
Average output ac power $\left(P_{\mathrm{ac}}\right)$ & $481.6 \mathrm{~W}$ & $477.05 \mathrm{~W}$ \\
Power loss $\left(P_{L}=P_{\mathrm{dc}}-P_{\mathrm{ac}}\right)$ & $47.6 \mathrm{~W}$ & $52.15 \mathrm{~W}$ \\
\hline \hline
\end{tabular}

into conduction path, and " $2 n$ " switches for bypassing of the " $n$ " remaining cell capacitors. During bypass of the " $n$ " cell capacitors using switches $S_{2} S_{3} S_{5} S_{6}$ in each cell, the current conduction path is through diodes $\left(D_{2} D_{3} D_{5} D_{6}\right)$ for $i_{a}<0$, and through IGBTs $\left(T_{2} T_{3} T_{5} T_{6}\right)$ for $i_{a} \geq 0$. During insertion of the cell capacitors into conduction path, the current flow through the IGBT or diode depends on the individual switch location within each cell (see Table II). Fig. 5 depicts MMC upper and lower arm currents and their corresponding insertion functions. Observe that the conduction period of diodes $\left(D_{2} D_{3} D_{5} D_{6}\right)$ and IGBTs $\left(T_{2} T_{3} T_{5} T_{6}\right)$ of the switches $S_{2} S_{3} S_{5} S_{6}$, which are used to bypass cell capacitors, vary significantly with the magnitude and polarity of the dc component of the arm current $I_{d}$ ( $I_{d}$ varies strongly with dc power being exchanged) [see Fig. 5(a)]. The current conduction between $\beta$ and $\pi-\beta$ in Fig. 5(a) represents conduction period of diodes $\left(D_{2} D_{3} D_{5} D_{6}\right)$ during bypass of the cell capacitor of individual cells, where $I_{0}$ represents the peak fundamental components of the arm currents, and $\beta=\sin ^{-1} I_{d} / I_{0}$. Recall that $I_{d}=1 / 3 I_{\mathrm{dc}}\left(I_{\mathrm{dc}}\right.$ is the dc-link current) and $I_{0}=1 / 2 I_{m}$ (where, $I_{m}$ represents peak of the output phase current). From Figs. 3(b) and 5(a) and Table II, currents in the IGBTs and diodes of the switches being used to bypass the cell capacitors in each phase leg are $i_{\mathrm{Tb}}(t)=i_{\mathrm{la}}$ for $\pi-\beta<\omega t \leq 2 \pi+\beta$ and $i_{\mathrm{Db}}(t)=-i_{\mathrm{la}}$ for $\beta<\omega t \leq \pi-\beta$.

Using these definitions of $i_{\mathrm{Tb}}(t)$ and $i_{\mathrm{Db}}(t)$, the equivalent average and root-mean-square currents in the IGBTs and diodes of the switches being employed to bypass " $n$ " cell capacitors are approximated by

$$
\begin{aligned}
\bar{I}_{\mathrm{Tb}} & =\left[\frac{1}{2} I_{d}(\pi+2 \beta)+\sqrt{I_{0}^{2}-I_{d}^{2}}\right] / \pi \\
\bar{I}_{\mathrm{Db}} & =\left\lfloor\left[\frac{1}{2} I_{d}(\pi-2 \beta)-\sqrt{I_{0}^{2}-I_{d}^{2}}\right] / \pi \mid\right. \\
I_{\text {rms_Tb }}^{2} & =\left[\left(I_{d}^{2}+\frac{1}{2} I_{0}^{2}\right)(\pi+2 \beta)+3 I_{d} \sqrt{I_{0}^{2}-I_{d}^{2}}\right] / 2 \pi
\end{aligned}
$$

$$
I_{\mathrm{rmsDb}}^{2}=\left[\left(I_{d}^{2}+\frac{1}{2} I_{0}^{2}\right)(\pi-2 \beta)-3 I_{d} \sqrt{I_{0}^{2}-I_{d}^{2}}\right] / 2 \pi .
$$

Using expressions (7)-(10), the on-state losses of the switches $S_{2} S_{3}$ and $S_{5} S_{6}$ being used to bypass " $n$ " cell capacitors from each

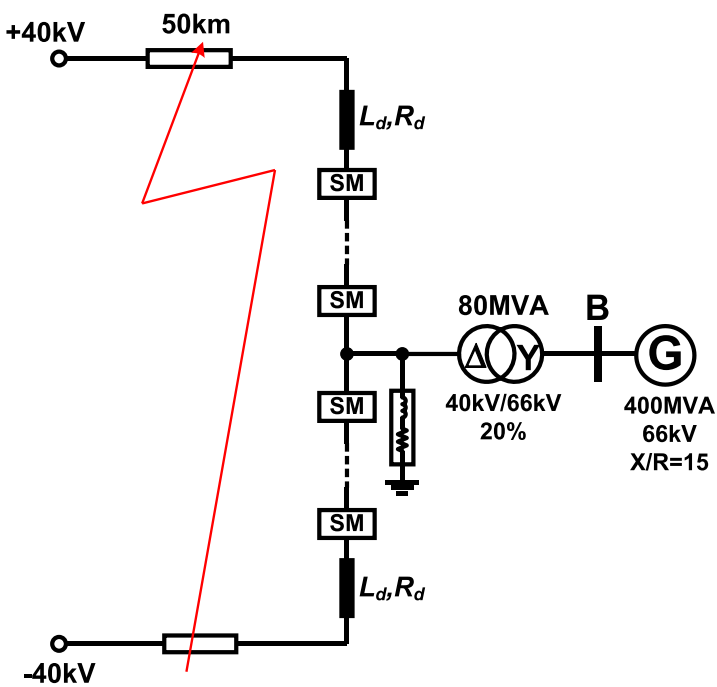

Fig. 9. Converter terminal of monopole HVDC link $\left(R_{\mathrm{dc}}=\right.$ $9 \mathrm{~m} \Omega / \mathrm{km}, L_{\mathrm{dc}}=1.35 \mathrm{mH} / \mathrm{km}$, and $\left.C_{\mathrm{dc}}=0.23 \mu \mathrm{F} / \mathrm{km}\right)$.

phase leg are computed using

$$
\begin{aligned}
& P_{\mathrm{Tb}}=n\left[V_{T 0} \bar{I}_{\mathrm{Tb}}+\frac{1}{2} R_{\mathrm{Ton}} I_{\mathrm{rms}-\mathrm{Tb}}^{2}\right] \\
& P_{\mathrm{Db}}=n\left[V_{D 0} \bar{I}_{\mathrm{Db}}+\frac{1}{2} R_{\mathrm{Don}} I_{r m s_{-} \mathrm{Db}^{2}}\right]
\end{aligned}
$$

where $R_{\mathrm{Don}}$ and $R_{\text {Ton }}$, and $V_{\mathrm{Do}}$ and $V_{\text {To }}$ are on-state resistances and threshold voltages of the diode and IGBT that form a single composite switch $S_{2} S_{3}$ and $S_{5} S_{6}$, respectively. However, insertion of " $n$ " cell capacitors using switch states that generate " $V_{c}$ " and " $2 V_{c}$ " from each arm insert " $n$ " switches of mixed combinations (diodes and IGBTs) into conduction path [see Table II and Fig. 3(b)]. This introduces some imperfections, which are handled in this paper using average on-state resistance and threshold voltage of the IGBT and diode $\left(R_{\mathrm{on}}=1 / 2\left(R_{\text {Don }}+R_{\text {Ton }}\right)\right.$ and $\left.V_{T}=1 / 2\left(V_{\mathrm{Do}}+V_{\mathrm{To}}\right)\right)$, and their equivalent average and rootmean-square currents are approximated by

$$
\begin{aligned}
\bar{I}_{\mathrm{Ti}} & =\frac{1}{2 \pi}\left|\int_{\beta}^{\pi-\beta} i_{\mathrm{la}} d t\right|+\frac{1}{2 \pi} \int_{\pi-\beta}^{2 \pi+\beta} i_{\mathrm{la}} d t \\
& =\bar{I}_{\mathrm{Db}}+\bar{I}_{\mathrm{Tb}} \\
I_{\mathrm{rms} T \mathrm{Ti}}^{2} & =\frac{1}{2 \pi} \int_{\beta}^{2 \pi+\beta} i_{\mathrm{la}}^{2} d t=\left(I_{d}^{2}+\frac{1}{2} I_{0}^{2}\right) .
\end{aligned}
$$

Using expressions (7)-(10), the on-state losses of the switches $S_{2} S_{3}$ and $S_{5} S_{6}$ being used to bypass " $n$ " cell capacitors from each phase leg are computed using

$$
P_{\mathrm{Ti}}=n\left[V_{\mathrm{T} 0} \bar{I}_{\mathrm{Ti}}+R_{\mathrm{Ton}} I_{\text {rms_Ti }}^{2}\right] .
$$

Notice that (7)-(15) could be applied to HB-MMC [see cell in Fig. 3(c)] should " $1 / 2$ " in (11) and (12) is omitted.

To demonstrate the improved efficiency of the MMC that uses proposed cell in Fig. 3(b) compared to that uses HB cell, the on-state losses of MMCs that employ these two cells are presented in Table III. The on-state loss estimated in Table III are computed, assuming the following rated parameters: 1052-MVA 


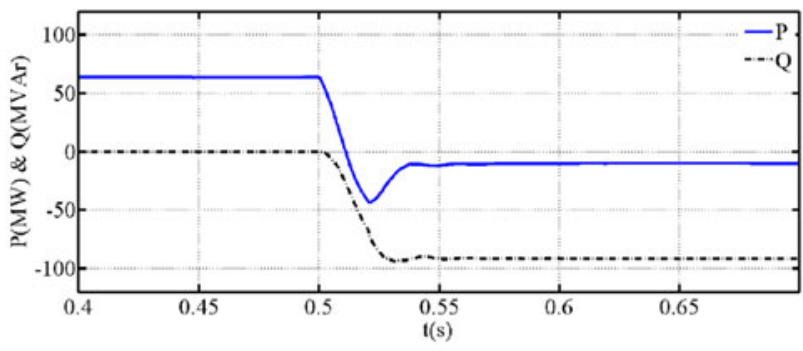

(a)

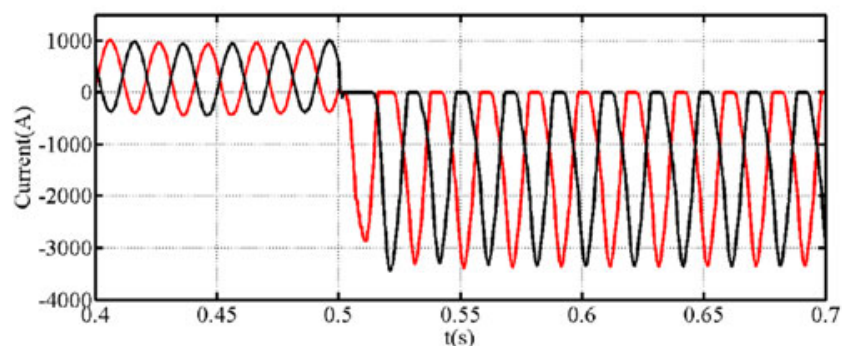

(c)

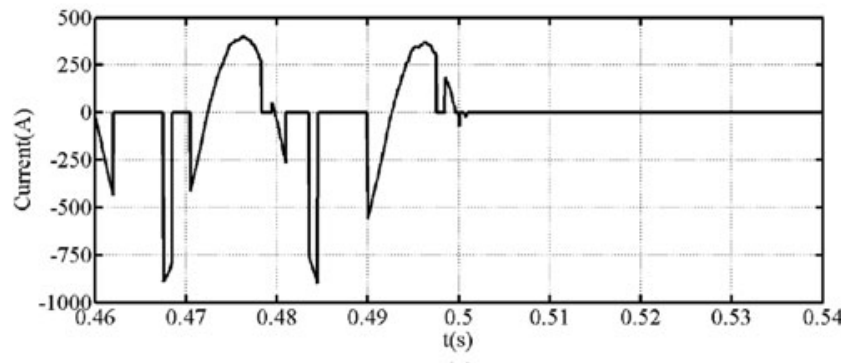

(e)

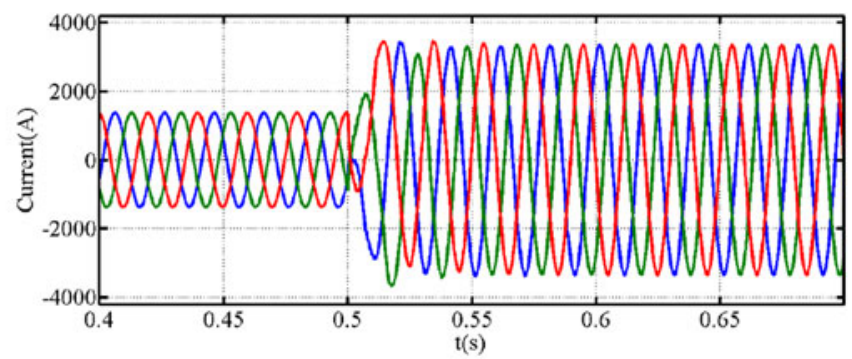

(b)

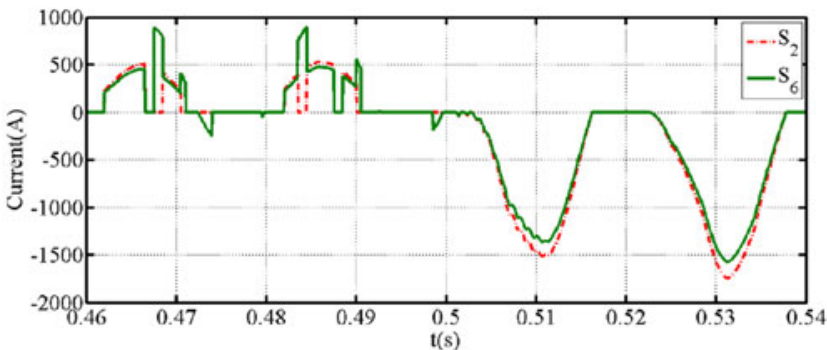

(d)

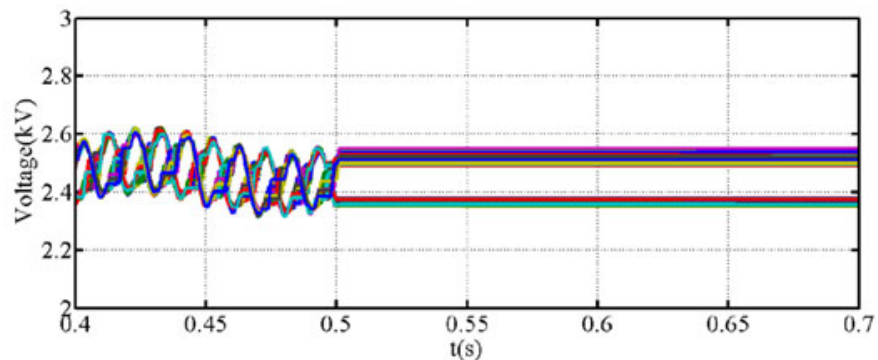

(f)

Fig. 10. Selected waveforms illustrate behave of the proposed MMC during a pole-to-pole dc short-circuit fault. (a) Active and reactive powers measured at bus B. (b) Three-phase currents converter presents at the low-voltage side of the interfacing transformer. (c) Phase " $a$ " upper and lower arm currents. (d) Current waveforms in the switching devices ( $S_{2}$ and $S_{6}$ in the first cell of the upper arm of phase " $a$ ") zoomed around the instant when the fault is initiated. (e) Current in the switching device $S_{1}$, first cell of the upper arm of phase " $a$ ") zoomed around the instant when the fault is initiated. (f) Phase " $a$ " cell capacitor voltages.

converter with $640-\mathrm{kV}( \pm 320-\mathrm{kV})$ dc-link voltage; 352-kV lineto-line ac voltage, which is corresponding to 0.9 modulation index; and considering three operating points shown in Table III. In this study, 4.5-kV IGBT (T1800GB45A) from Westcode is assumed, with a voltage stress per switch of $2.0 \mathrm{kV}$. Analytical and simulation on-state losses summarized in Table III indicate that the MMC with the proposed cell arrangement has lower on-state loss than the conventional HB-MMC. It has been found that the presented analytical method overestimates the on-state losses of both converters being compared by a maximum of $6 \%$ with respect to that being computed using detailed simulation (on-state loss of individual device is calculated using measured currents and then added together), considering three operating points in Table III.

For calculations of switching loss, IGBT turn-on and turn-off energy losses $\left(E_{\text {on }}\right.$ and $\left.E_{\text {off }}\right)$ from datasheet are approximated as $E_{\mathrm{on}}=-270.7 \times 10^{-12} i_{\mathrm{on}}^{4}+1.812 \times 10^{-6} i_{\mathrm{on}}^{3}-2.744 \times$ $10^{-3} i_{\text {on }}^{2}+4.953 i_{\text {on }}$ and $E_{\text {off }}=-3.11 \times 10^{-9} i_{\text {off }}^{4}+11.57 \times$ $10^{-6} i_{\text {off }}^{3}-13.65 \times 10^{-3} i_{\text {off }}^{2}+8.921 i_{\text {off }}$, where $i_{\text {on }}$ and $i_{\text {off }}$ are currents at the turn-on and turn-off instances. IGBT switching loss is obtained from $P_{\mathrm{sw}}=\left(f_{\text {on }} \bar{E}_{\text {on }}+f_{\text {off }} \bar{E}_{\text {off }}\right)$, where $\bar{E}_{\text {on }}$ and $\bar{E}_{\text {off }}$ are average turn-on and turn-off energy losses over one fundamental cycle, respectively, and $f_{\text {on }}$ and $f_{\text {off }}$ are switching frequencies. With freewheeling diodes recovery losses being neglected, Tables IV and V show that the switching losses and total semiconductor losses of the MMC with the proposed cell arrangement are lower than that of the HB-MMC. The results in Tables III-V all indicate that the MMC that uses the proposed cell arrangement outperforms the HB-MMC from semiconductor loss point of view. See [36] and [37] for more detailed method for semiconductor loss calculations, where diode recovery losses are taken into account. With power loss cost assumed to be $3 \mathrm{M} € / \mathrm{MW}$ per year [38], the savings over project lifetime of 30 years between the two converters are displayed in Table V.

\section{REDUCED SCALE EXPERIMENTATIONS}

This section uses reduced scale experimentations to compare the performance of the MMC that employs the presented cell in Fig. 3(b) against that uses the conventional HB cell. Fig. 6 shows schematic diagrams and prototypes of both converters, 


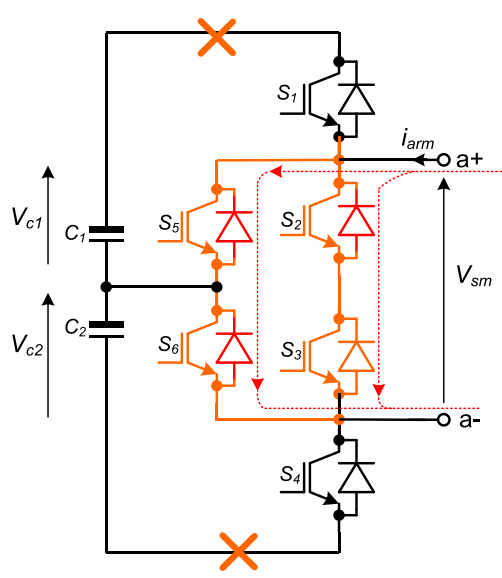

(a)

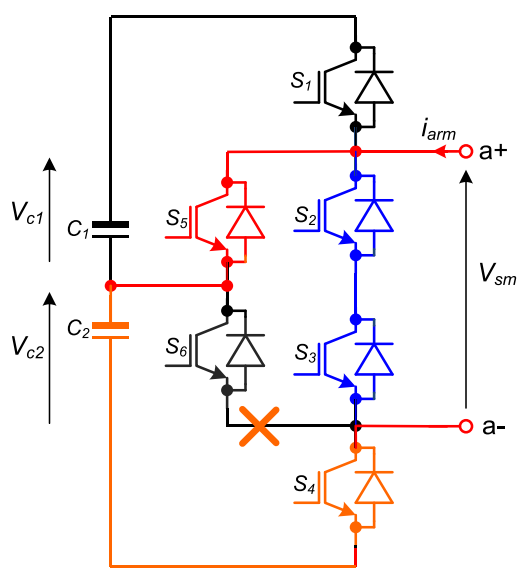

(d)

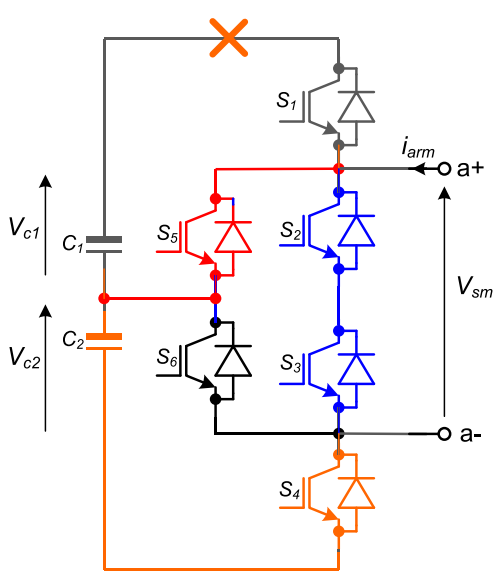

(b)

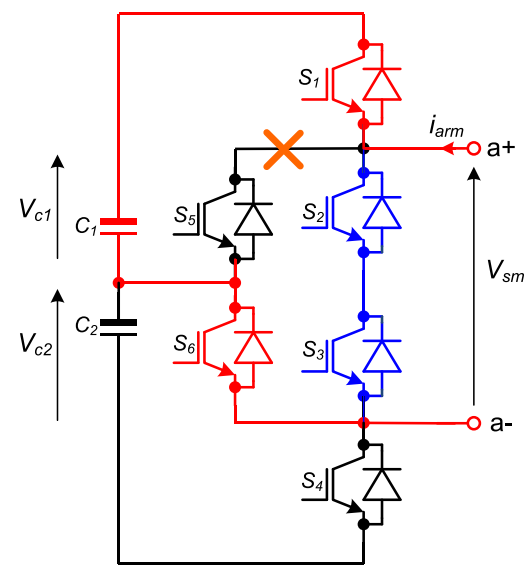

(e)

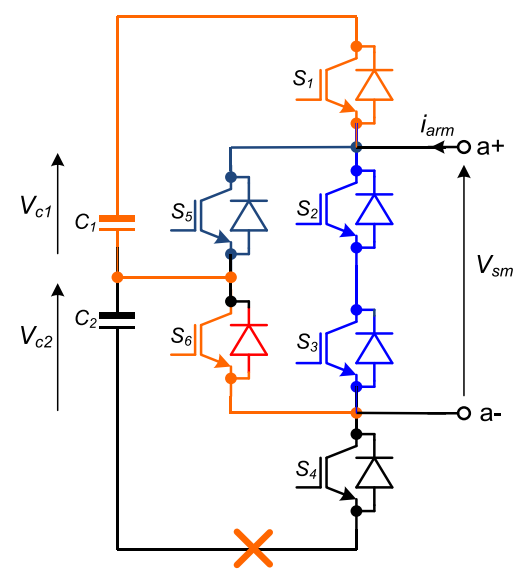

(c)

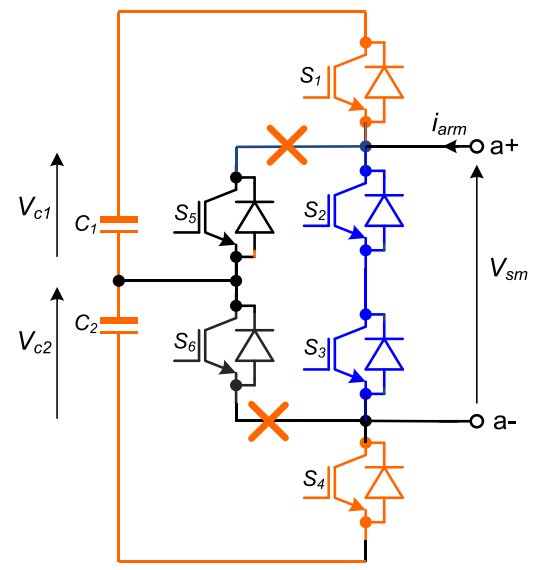

(f)

Fig. 11. Examples of exploitable switch states to facilitate partial or full bypass of the faulty cells and continued converter operation during switch devices open-circuit faults or cell capacitor failures. (a) Simultaneous open circuit faults of switches $S_{1}$ and $S_{4}$, or failure of capacitors $C_{1}$ and $C_{2}$. (b) Open-circuit fault in the switches $S_{1}$, or failure of capacitors $C_{1}$. (c) Open-circuit fault in the switches $S_{4}$, or failure of capacitors $C_{2}$. (d) Open-circuit fault in the switches $S_{6}$. (e) Open-circuit fault in the switches $S_{5}$. (f) Simultaneous open circuit faults in the switches $S_{5}$ and $S_{6}$.

with test rig parameters listed in Table VI. Modulation and capacitor voltage balancing are programmed on low-cost 32-bit Cypress microcontroller (CY8CKIT-050 PSoC 5LP). Due to the reduced number of cells per arm (four cells), pulse width modulation with 2.4-kHz carrier frequency is used (carriers are arranged in phase disposition fashion). Experimental waveforms presented in Figs. 7(a)-(e) and 8(a)-(e) show that both MMCs produce similar output voltages and currents, upper and lower arm currents, and cell capacitor voltages. However, samples of the gating signals in Figs. 7(f) and 8(f) indicate that the proposed cell is expected to have better loss distribution as the arm current will be evenly shared among $S_{a 2}, S_{a 3}, S_{a 5}$, and $S_{a 6}$ when the cell generates zero-voltage level (when gating signals of $S_{a 2}$ and $S_{a 4}$ in Fig. 7(f) are both high). Summary of the overall semiconductor losses (on-state plus switching) of both converters obtained from experiments in Table VII confirms the improved loss performance of the proposed cell. But the figures for the semiconductor losses displayed are extremely high due to the use of low-cost IGBTs with high on-state voltage drop employed (30 A, 1200-V IGBT, STGW30NC120HD, while the actual average voltage stress per cell capacitor and IGBT is $70 \mathrm{~V})$. Because of the IGBTs overrating, it is observed that the peak fundamental voltages obtained from both prototypes are 102.1 and $100.9 \mathrm{~V}$ for the proposed and HB cells, respectively, compared to theoretical peak voltage $V_{m}={ }^{1} / 2 m V_{\mathrm{dc}}={ }^{1} / 2 \times$ $0.8 \times 280=112 \mathrm{~V}$. Notice that with the measured dc-link current $=1.89 \mathrm{~A}$ and output active power $=481.6 \mathrm{~W}$ (proposed cell), the effective dc voltage, excluding the total devices voltage drop and losses in the switching devices could be approximated by $V_{\mathrm{dc}}=P_{\mathrm{dc}} / I_{\mathrm{dc}}=481.6 / 1.89 \approx 254.8 \mathrm{~V} \approx V_{c}$, assuming switching losses in the reduced scale prototype is negligible. This discussion indicates that the total dc voltage drop in the switching devices is $280-254.8=25.2 \mathrm{~V}$, power loss $=25.2 \times 1.89 \approx 47.6 \mathrm{~W}$, and peak phase voltage $V_{m}=1 / 2 m V_{c}=1 / 2 \times 0.8 \times 254.8=101.92 \mathrm{~V}$, which are in line with the measured loss and peak phase voltage in Table VII and Fig. 7(b). Similarly, for the prototype of the HB-MMC, the effective dc voltage $V_{\mathrm{dc}}=\mathrm{V}_{\mathrm{c}}$ 


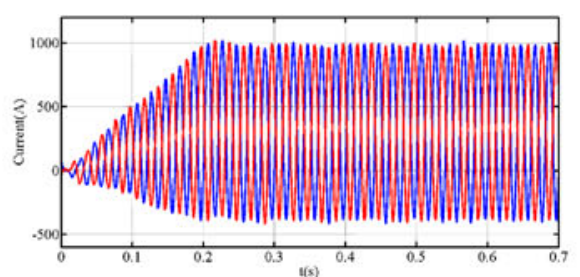

(a)

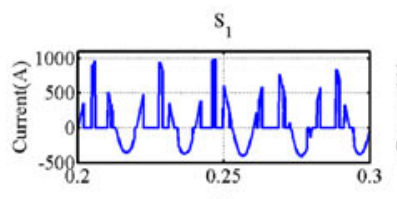

$\mathrm{S}_{4}$

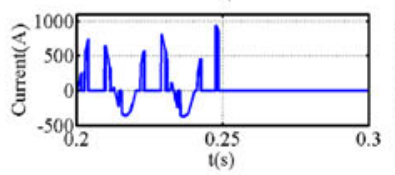

(c)

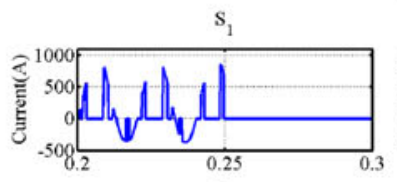

$\mathrm{S}_{4}$

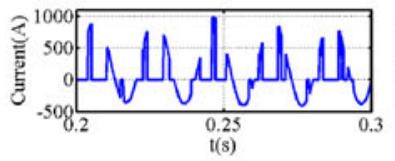

(d)

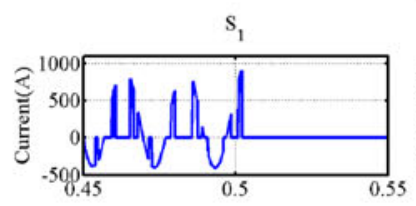

$\mathrm{S}_{4}$

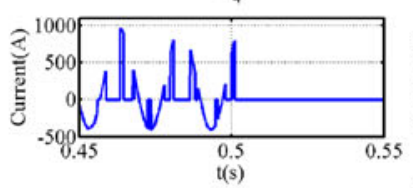

(e)

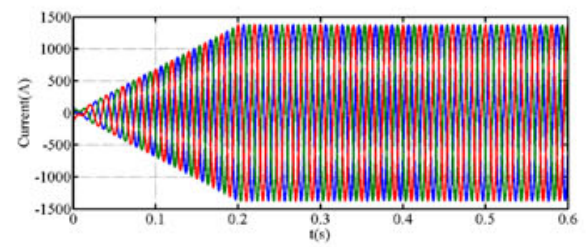

(f)

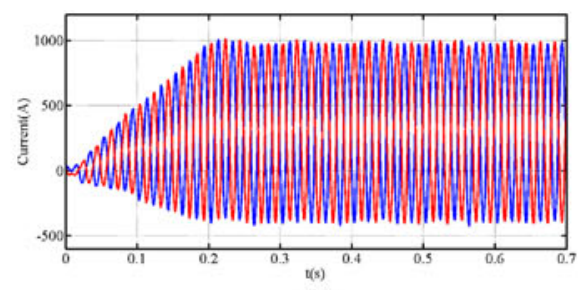

(b)

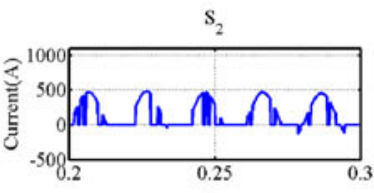

$\mathrm{s}_{6}$
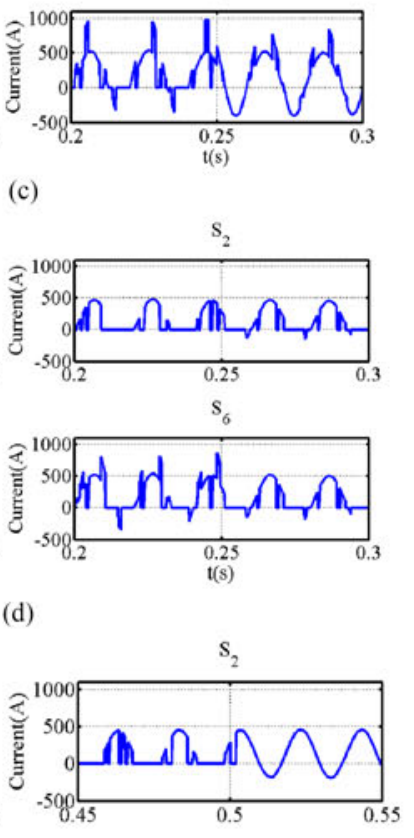

$\mathrm{s}_{6}$
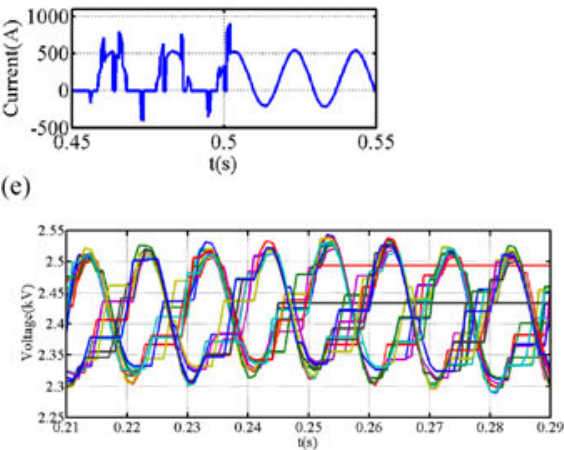

(g)

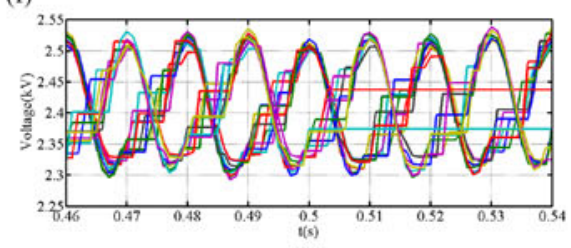

(h)

Fig. 12. Waveforms illustrate easy of internal fault handling in the proposed cell. (a) Phase " $a$ " upper and lower arm currents. (b) Phase " $b$ " upper and lower arm

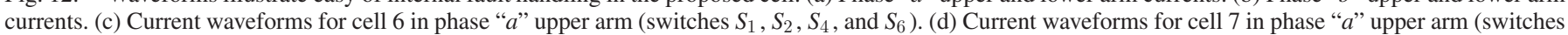
$S_{1}, S_{2}, S_{4}$, and $S_{6}$ ). (e) Current waveforms for cell 4 in phase " $b$ " lower arm (switches $S_{1}, S_{2}, S_{4}$, and $S_{6}$ ). (f) Three-phase output current. (g) Samples of phase " $a$ " upper and lower arm cell capacitors. (h) Samples of phase " $b$ " upper and lower arm cell capacitors. 


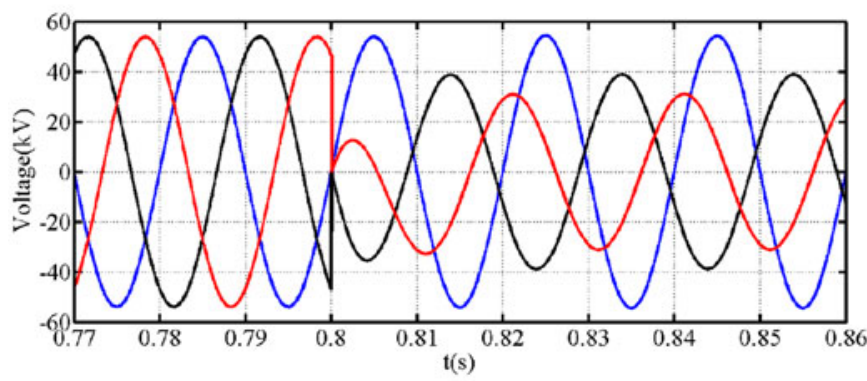

(a)

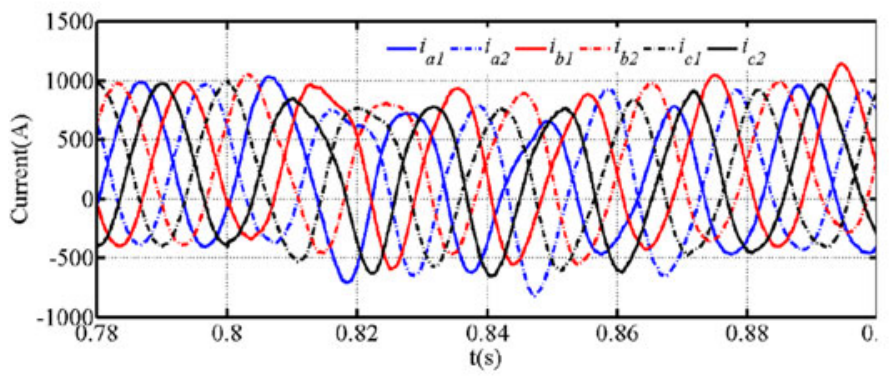

(c)

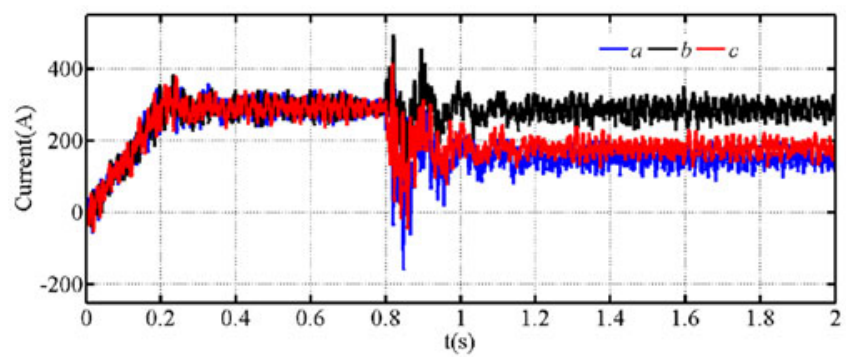

(e)

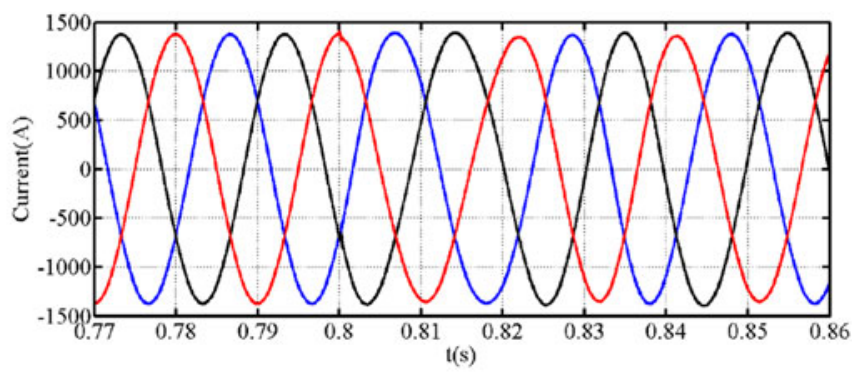

(b)

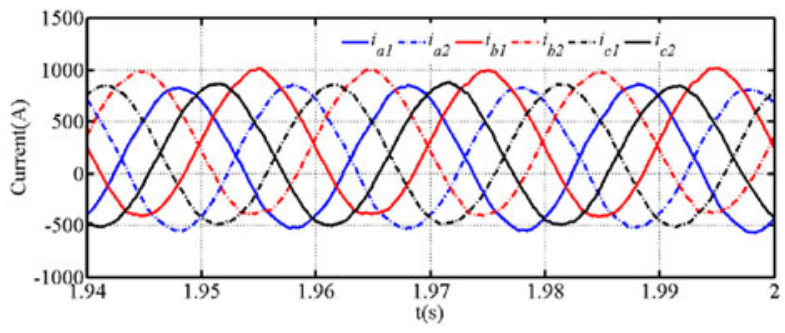

(d)

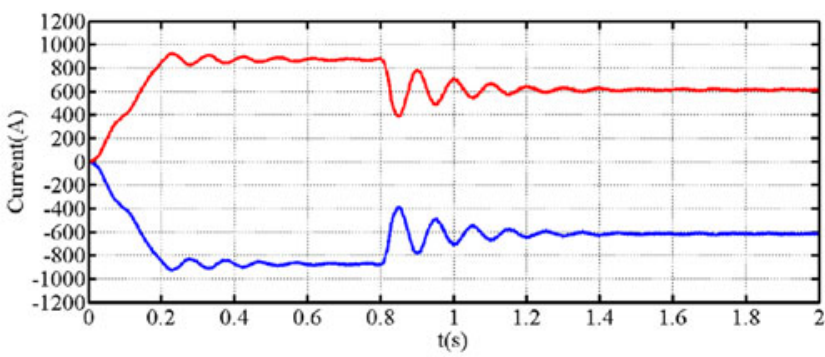

(f)

Fig. 13. Waveforms that illustrate the performance the MMC that employs the proposed cell during unbalanced condition. (a) Three-phase voltages measured at B. (b) Three-phase currents at converter terminal, measured at the low-voltage side of the interfacing transformer. (c) Upper and lower arm currents of the three phases, zoomed around transition between balanced to unbalanced condition. (d) Upper and lower arm currents of the three phases during new steady state when system operates under unbalanced condition. (e) Common-mode currents of the three phases, $1 / 2\left(i_{\mathrm{abc} 1}+i_{\mathrm{abc} 2}\right)$. (f) Positive and negative dc-link currents.

$=477.1 / 1.89 \approx 252.4 \mathrm{~V}$, peak phase voltage $V_{m}=$ $1 / 2 m V_{c}=1 / 2 \times 0.8 \times 252.4=100.96 \mathrm{~V}$, and power loss $=$ $(280-252.4) \times 1.89 \approx 52.17 \mathrm{~W}$. These results also agree with experimental results summarized in Table VII and Fig. 8(b). Although on a per unit basis, the magnitudes of the experimental losses are out of step with that expected in the full-scale HVDC converter, it does not invalidate the superiority of the proposed cell over the HB cell in terms of semiconductor loss.

\section{System Simulations}

This section presents system simulations of the MMC that adopts the proposed cell, considering dc short-circuit fault and continued operation when some cells fail. Fig. 9 shows the test system that represents 84-MVA converter terminal of symmetrical monopole HVDC link, with $\pm 40-\mathrm{kV}$ dc-link voltage, connected to 66-kV ac grid through 80-MVA, 40-kV/66-kV ac transformer with $20 \%$ per unit reactance. The proposed MMC is modeled using a detailed switch model, with 16 cells (32 cell capacitors) per arm, arm inductance $L_{d}=10 \mathrm{mH}$, and each cell capacitance is rated at $2.5 \mathrm{kV}$ and $8 \mathrm{mF}$. DC cable parameters are given in Fig. 9, with ac-side high-impedance grounding adopted as suggested in [39] and [40] to define the insulation level for the dc side. In this example, the MMC being studied is equipped with active and reactive power controllers, a fundamental current controller in $d q$ frame, circulating current controller and cell capacitor voltage balancing (overall control system is similar to that in [41]). At startup, the converter station is commanded to inject active power of $64 \mathrm{MW}$ into ac grid, at bus B at unity power factor. A permanent pole-to-pole dc short-circuit fault is applied in the middle of the dc line at time $t=0.5 \mathrm{~s}$, and active power injection into B is reduced to zero immediately, with gating signals to converter switches inhibited after $50 \mu \mathrm{s}$ from fault initiation.

\section{A. Pole-to-Pole DC Short-Circuit Fault}

Fig. 10 presents selected waveforms that illustrate the behavior of the MMC that employs the proposed cell when it is subjected to a pole-to-pole dc short-circuit fault. Fig. 10(a) 
and (b) displays active and reactive power converter exchanges with the ac grid " $G$," measured at bus B, and ac currents in the low-voltage side of the interfacing transformer. Fig. 10(c) shows that phase " $a$ " upper and lower arm currents are well controlled during normal operation, with second-order harmonic currents in the converter arms being suppressed. During the dc short-circuit fault, significant overlap is observed between the upper and lower arms, which is caused by large arm inductances and transformer leakage inductances (these overlaps indicate short periods of simultaneous conduction of the upper and lower arms of the same phase leg). Fig. 10(d) shows current waveforms in the switches $S_{2}$ and $S_{6}$, which are exploited for generation of zero-voltage level at each cell during normal operation and to share the current stress when the converter is blocked during pole-to-pole dc short-circuit fault. In this illustration, the on-state resistances for the diodes of the composite switches $S_{2}$ and $S_{3}$ are deliberately set to be $90 \%$ of that of the $S_{5}$ and $S_{6}$ to mimic the potential mismatch in the typical semiconductor switches that may be employed (see datasheet of IGBT T1800GB45A for on-state resistance). Observe that the arm current is shared well between the parallel paths provided by the diodes of the switches $S_{2}$ and $S_{3}$, and $S_{5}$, and $S_{6}$. This clearly supports the case for elimination of the thyristors being used in the HB cell in Fig. 3(c) to relieve diodes of the main switches that bypass the cell capacitors from excessive overcurrent during dc short-circuit fault. Fig. 10(e) presents the current waveform in the switch $S_{1}$, which is in series with capacitor $C_{1}$ of each cell. Observe that the current in this switch has dropped to zero when the converter is blocked as expected (no discharge of the cell capacitor). Fig. 10(f) shows phase " $a$ " cell capacitor voltages remain balanced in the prefault condition and unchanged when the converter is blocked during a fault period. The above discussions show that the MMC that uses the proposed cell retains all the attributes and adheres to the same fundamental equations that describe the steady-state and dynamic operation of the HB-MMC, while offering higher efficiency than HB-MMC and eliminating the unidirectional current sharing thyristor being used in the HB-MMC.

\section{B. Continued Operation With Multiple Cell Faults}

Fig. 11 shows some of the possible switching restrictions that would be applied to facilitate continued converter operation during cell capacitors failure or switching devices open-circuit faults, depending on the exact fault location. For example, the fault scenario depicted in Fig. 11(a) necessitates full bypass of the presented cell (two voltage levels will be lost per affected cell), while any of the other fault scenarios in Fig. 11(b) and (c) could restrict the number of voltage levels to be generated to two ( $V_{c}$ and 0 , should $V_{c 2}=V_{c 1}=V_{c}$ ), with one switch state available for generation of each voltage level (loss of one voltage level per affected cell). In these two fault scenarios, the switch state in Fig. 11(a) could be used to generate zero voltage at reduced semiconductor loss. Fig. 11(d) and (e) summarizes examples of switch open-circuit faults that do not affect the number of voltage level each cell could generate and limit number of possible ways to generate voltage level " $V_{c}$ " to 1 .

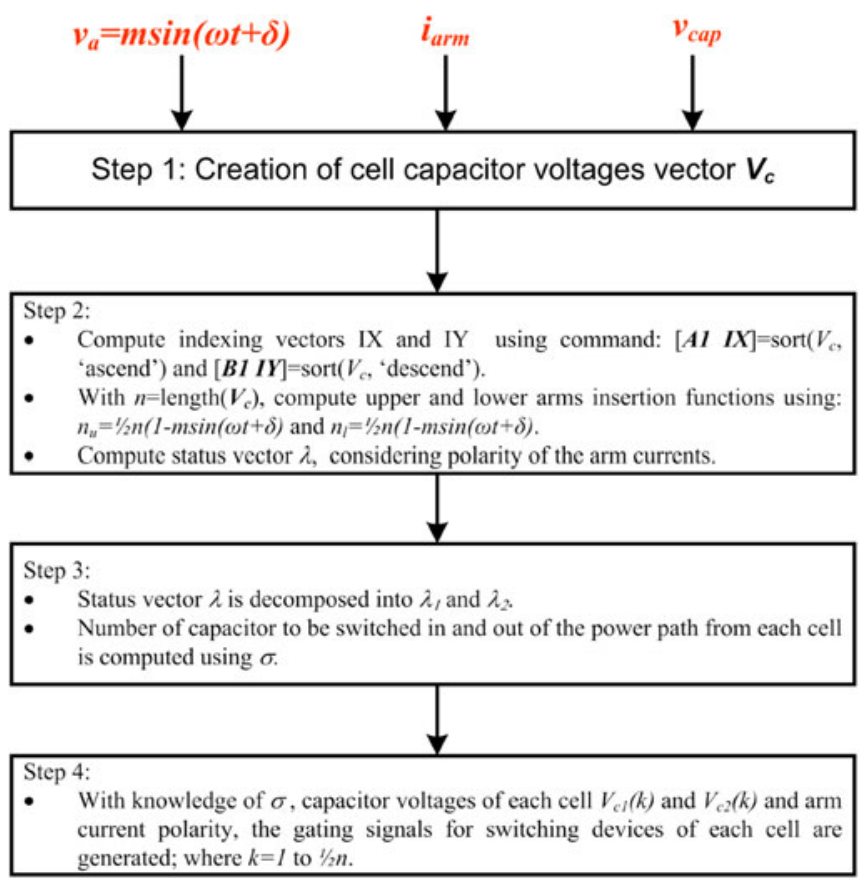

Fig. 14. Flowchart that summarizes implementation of method II of the capacitor voltage balancing, which is employed in this paper.

Additionally, these fault scenarios do not permit generation of "0" voltage level at reduced losses. Fig. 11(f) displays simultaneous fault scenario in the switches $S_{5}$ and $S_{6}$ that will make the faulty cell incapable of generating voltage level " $V_{c}$," and as a result, the affected cell could be reconfigured to operate as a two-level unipolar cell capable of generating 0 and $2 V_{c}$. When a large number of cells suffer from this type of simultaneous fault, all cells in the affected phase leg could be reconfigured as stated above, without any sacrifice to maximum fundamental output voltage that could be generated. For illustration of internal fault management of the proposed cell, a hypothetical case assumes that cells 6 and 7 in the upper arm of phase " $a$ " of the test system in Fig. 9 are subjected to open-circuit fault scenarios depicted in Fig. 11(c) and (b) at $t=0.25 \mathrm{~s}$, and at $t=0.5 \mathrm{~s}$, while cell 4 in the lower arm of phase " $b$ " is subjected to simultaneous open-circuit fault scenario in Fig. 11(a). In the prefault condition, the test system being studied injects $64 \mathrm{MW}$ into the ac grid at unity power factor, with its power set point unchanged when some of its cells fail as stated earlier. The following simplifications are assumed during implementation of the internal fault management, which are summarized as follows.

1) Fault location and type are detected instantly; thus, a fault management scheme for affected arm is enabled immediately.

2) Information of fault location is used to identify the affected and unaffected cell capacitors; hence, status vector $(\Psi)$ for the affected arm that contains zeros and ones is generated, with zeros and ones pointing to the locations of the unaffected and affected capacitors within each cell in the faulty arm. For an MMC with $n$ cell capacitors, and $M$ faulty cell, status vector is $\Psi i=\delta(i-k)$, where $\delta$ is the 
TABLE VIII

Global Comparison Between the Proposed Cell in Fig. 3(B) and Equivalent HB Cells in Fig. 3(C)

\begin{tabular}{|c|c|c|}
\hline & Half-bridge cell & Proposed cell \\
\hline Number of IGBTs & 4 (per two cells) & 6 (per cell) \\
\hline Number of protective thyristors & 2 (per two cells) & 0 \\
\hline Number of bypass switches & 2 (per two cells) & 0 \\
\hline Number cell capacitors & 2 (per two cells) & 2 (per cells) \\
\hline $\begin{array}{l}\text { Devices dedicated for handling dc-fault current } \\
\text { converter is blocked during dc short circuit }\end{array}$ & $\begin{array}{c}\text { Freewheeling diodes of switches } S_{2} \text { and } \\
S_{4} \text {, and thyristors } T_{1} \text { and } T_{2}\end{array}$ & $\begin{array}{l}\text { Freewheeling diodes of switches } S_{2}, \\
\text { and } S_{3}, S_{5} S_{6}\end{array}$ \\
\hline $\begin{array}{l}\text { Internal fault management should one or limited } \\
\text { number of cells fail }\end{array}$ & Bypass switches & Switches $S_{2}, S_{3}, S_{5}$, and $S_{6}$ \\
\hline Power loss distribution & $\begin{array}{l}\text { Switching devices } S_{2} \text { and } S_{4} \text { that } \\
\text { generate zero-voltage states dissipate } \\
\text { more losses than } S_{1} \text { and } S_{3}\end{array}$ & $\begin{array}{c}\text { Better than HB cell as the } \\
\text { semiconductor losses in the main } \\
\text { switches that generate ' } 0 \text { ' voltage } \\
\text { level are distributed between } S_{2} \text { and } \\
S_{3} \text {, and } S_{5} \text { and } S_{6} \text {. }\end{array}$ \\
\hline Semiconductor loss & Low & Lower than HB cell, see Table V \\
\hline Number of isolated dc-dc converter for gate drives & 2 (per two cells) & 1 (per cell) \\
\hline Dynamic response & good & The same as HB-MMC \\
\hline
\end{tabular}

Dirac function and it is defined as $\delta(i-k)=0 \forall i \neq k$ and $\delta(i-k)=1 \forall i=k, i=1$ to $n$, and $k$ is the natural number that stands for location of the faulty cell.

3) Each affected capacitor $\left(C_{i}\right)$ is omitted from the group of capacitors to be selected to synthesize different output voltages by setting its corresponding capacitor voltage $V_{\text {ci }}=2 \times \max \left(V_{c}\right)$ for $i_{\text {arm }} \geq 0$ and $V_{\text {ci }}=0.5 \times$ $\min \left(V_{c}\right)$ for $i_{\text {arm }}<0$, where $V_{c}=V_{c 1}, V_{c 2}, \ldots, V_{\text {cn }}$.

Based on the outlined points, the gating signals for the switching devices of the faulty cells are modified.

Fig. 12 shows simulation waveforms for the fault scenarios described above. These waveforms indicate that the MMC that uses the proposed cell can manage its internal cell faults safely as that in the HB-MMC case. Simulation waveforms for the hypothetical case presented in Fig. 12 (time for fault detection and needed for activation of the fault management are assumed to be infinitesimal) show no evidence of transients in the arm or output phase currents when partial bypass of cells 6 and 7 are initiated at $t=0.25 \mathrm{~s}$, and complete bypass of the cell 4 is activated at $t=0.5 \mathrm{~s}$ [see Fig. 12(a), (b), and (f)]. Current waveforms measured in the switches of cells 6 and 7 in the upper arm of phase " $a$ " and of cell 4 in the lower arm of phase " $b$ " in Fig. 12(c)-(e) show seamless partial or complete exclusion of the faulty section of the cells, with the voltage across the affected capacitors remaining unchanged, avoiding any catastrophic outcome that may result from incorrect switching of the affected cells. The above discussions show that the MMC that uses the proposed cell is able to fully or partially bypass the faulty cells, without the need for mechanical bypass switches to be installed in each cell required as in the conventional $\mathrm{HB}$ cell.

\section{Unbalanced Operation}

This section examines the performance of the MMC that adopts the proposed cell during unbalanced operation initiated by deliberate connection of $1.2-$ and $0.8-\Omega$ resistors between phase $b$ and ground and $c$ and ground at $t=0.8 \mathrm{~s}$, and results for this case are displayed in Fig. 13. Fig. 13(a) and (b) displays three-phase voltages measured at bus $\mathrm{B}$ and currents at converter terminal (measured at the low-voltage side of the interfacing transformer). Observe that although three-phase voltages at the grid side are severely unbalanced, the currents the converter injects exhibit limited unbalance as expected. The plots for upper and lower arm currents in Fig. 13(c) and (d), commonmode currents in Fig. 13(e), and dc-link currents in Fig. 13(f) show no penetration of second-order harmonic into the dc positive and negative dc-link currents, with the second-harmonic currents in converter arms suppressed. These are achieved with the conventional decoupled controller of the positive sequence currents in the $d q$ frame, and resonance-based controller for second-harmonic suppression in converter arms. The plot for the common-mode currents in Fig. 13(e) indicates that each converter phase contributes unequal dc currents to the dc-link current $\left(I_{\mathrm{dc}}\right)$, and this is in contrary to some of the control methods in the literature that advocate dc current balancing, which may lead to overcurrent of the phases that experience larger voltage depressions. The above discussions indicate that the MMC with the proposed cell could operate satisfactory under unbalanced condition as HB-MMC.

\section{BRIEF COMPARISON OF THE HB AND PROPOSED CEllS}

Table VIII summarizes the main similarities and differences between the HB and the proposed cell in Fig. 3(c) and (b), assuming that both cells use semiconductor switches with similar voltage and current ratings, and two HB cells are equivalent to one of the proposed cell in Fig. 3(b). Table VIII shows that both cells being compared have similar semiconductor areas, with the proposed cell in Fig. 3(b) offering the best overall performance and utilization of these semiconductor devices.

\section{CONCLUSION}

This paper presents an alternative cell arrangement that uses its zero-voltage level to reduce semiconductor losses of modular-type converters to less than that of the HB-MMC, should the two additional IGBTs incorporated into the propose 
cell (instead of two protective thyristors in equivalent HB cells) are utilized as described above. The same IGBTs being used to reduce semiconductor losses could be exploited to bypass the faulty cells during internal converter faults, thus making the use of mechanical bypass switch redundant. The presented simulation and experimental results show that the MMC that uses the proposed cell inherits all the attributes of the HBMMC, including internal fault management, scalability to highvoltage applications, and transient performance during ac and dc network faults. The viability of the proposed cell arrangement at device and system levels is confirmed using simulations.

\section{APPENDIX}

This appendix presents a flowchart that summarizes implementation of method II, which is employed to perform capacitor voltage balancing in this paper.

\section{REFERENCES}

[1] M. A. Perez, S. Bernet, J. Rodriguez, S. Kouro, and R. Lizana, "Circuit topologies, modeling, control schemes, and applications of modular multilevel converters," IEEE Trans. Power Electron., vol. 30, no. 1, pp. 4-17, Jan. 2015

[2] V. Dargahi, A. K. Sadigh, M. Abarzadeh, S. Eskandari, and K. A. Corzine, "A new family of modular multilevel converter based on modified flyingcapacitor multicell converters," IEEE Trans. Power Electron., vol. 30, no. 1, pp. 138-147, Jan. 2015.

[3] C. Oates, "Modular multilevel converter design for VSC HVDC applications," IEEE J. Emerg. Sel. Topics Power Electron., vol. 3, no. 2, pp. 505-515, Jun. 2014.

[4] G. P. Adam, K. H. Ahmed, and B. W. Williams, "Mixed cells modular multilevel converter," in Proc. 23rd IEEE Ind. Electron. Int. Symp., 2014, pp. $1390-1395$.

[5] C. Chen, G. P. Adam, S. Finney, J. Fletcher, and B. Williams, "H-bridge modular multilevel converter: Control strategy for improved DC fault ride-through capability without converter blocking," IET Power Electron., vol. 8, no. 10, pp. 1996-2008, Oct. 2015.

[6] J. Peralta, H. Saad, S. Dennetiere, J. Mahseredjian, and S. Nguefeu, "Detailed and averaged models for a 401-level MMC-HVDC system," IEEE Trans. Power Del., vol. 27, no. 3, pp. 1501-1508, Jul. 2012.

[7] R. Zeng, L. Xu, L. Yao, and B. W. Williams, "Design and operation of a hybrid modular multilevel converter," IEEE Trans. Power Electron., vol. 30, no. 3, pp. 1137-1146, Mar. 2015.

[8] C. Oates, K. Dyke, and D. Trainer, "The use of trapezoid waveforms within converters for HVDC," in Proc. 16th Eur. Conf. Power Electron. Appl., 2014, pp. 1-10.

[9] G. P. Adam, K. H. Ahmed, S. J. Finney, K. Bell, and B. W. Williams, "New breed of network fault-tolerant voltage-source-converter HVDC transmission system," IEEE Trans. Power Syst., vol. 28, no. 1, pp. 335-346, Feb. 2013.

[10] M. M. C. Merlin, T. C. Green, P. D. Mitcheson, D. R. Trainert, D. R. Critchley†, and R. W. Crookes, "A new hybrid multi-level voltage-source converter with DC fault blocking capability," in Proc. 9th IET Int. Conf. AC DC Power Transmiss., London, U.K., 2010, pp. 1-5.

[11] I. A. Gowaid, G. P. Adam, B. W. Williams, A. M. Massoud, and S. Ahmed, "The transition arm multilevel converter-A concept for medium and high voltage DC-DC transformers," in Proc. IEEE Int. Conf. Ind. Technol., 2015, pp. 3099-3104.

[12] S. Debnath, Q. Jiangchao, B. Bahrani, M. Saeedifard, and P. Barbosa, "Operation, control, and applications of the modular multilevel converter: A review," IEEE Trans. Power Electron., vol. 30, no. 1, pp. 37-53, Jan. 2015 .

[13] G. Adam and I. Davidson, "Robust and generic control of full-bridge modular multilevel converter high-voltage DC transmission systems," IEEE Trans. Power Del., vol. 30, no. 6, pp. 2468-2476, Dec. 2015.

[14] A. Nami, L. Jiaqi, F. Dijkhuizen, and G. D. Demetriades, "Modular multilevel converters for HVDC applications: Review on converter cells and functionalities," IEEE Trans. Power Electron., vol. 30, no. 1, pp. 18-36, Jan. 2015.
[15] M. Sleiman, H. F. Blanchette, K. Al-Haddad, L. A. Grégoire, and H. Kanaan, "A new 7L-PUC multi-cells modular multilevel converter for AC-AC and AC-DC applications," in Proc. 2015 IEEE Int. Conf. Ind. Tech., 2015, pp. 2514-2519.

[16] G. Bergna et al., "An energy-based controller for HVDC modular multilevel converter in decoupled double synchronous reference frame for voltage oscillation reduction," IEEE Trans. Ind. Electron., vol. 60, no. 6 , pp. 2360-2371, Jun. 2013.

[17] J. Kolb, F. Kammerer, M. Gommeringer, and M. Braun, "Cascaded control system of the modular multilevel converter for feeding variable-speed drives," IEEE Trans. Power Electron., vol. 30, no. 1, pp. 349-357, Jan. 2015

[18] G. P. Adam and B. W. Williams, "Half- and full-bridge modular multileve converter models for simulations of full-scale HVDC links and multiterminal DC grids," IEEE J. Emerg. Sel. Topics Power Electron., vol. 2, no. 4, pp. 1089-1108, Dec. 2014.

[19] G. P. Adam and B. W. Williams, "Multi-pole voltage source converter HVDC transmission systems," IET Gener, Transmiss. Distrib., vol. 10 no. 2, pp. 496-507, Feb. 4, 2016. [Online]. Available: http://digitallibrary.theiet.org/content/journals/10.1049/iet-gtd.2015.0894

[20] Q. Tu, Z. Xu, and L. Xu, "Reduced switching-frequency modulation and circulating current suppression for modular multilevel converters," IEEE Trans. Power Del., vol. 26, no. 3, pp. 2009-2017, Jul. 2011.

[21] C. Chao, G. P. Adam, S. Finney, J. Fletcher, and B. Williams, "H-bridge modular multi-level converter: Control strategy for improved DC fault ride-through capability without converter blocking," IET Power Electron., vol. 8, pp. 1996-2008, 2015.

[22] G. P. Adam and I. E. Davidson, "Robust and generic control of full-bridge modular multilevel converter high-voltage DC transmission systems," IEEE Trans. Power Del., vol. 30, no. 6, pp. 2468-2476, Dec. 2015.

[23] G. P. Adam, S. J. Finney, and B. W. Williams, "Enhanced control strategy of full-bridge modular multilevel converter," in Proc. Int. Conf. Renew. Energy Res. Appl., 2015, pp. 1432-1436.

[24] B. M. Espinoza, A. Mora, M. Diaz, and R. Cárdenas, "Balancing energy and low frequency operation of the modular multilevel converter in back to back configuration," in Proc. 10th Int. Conf. Ecol. Veh. Renew. Energies, 2015, pp. 1-9.

[25] N. Thitichaiworakorn, M. Hagiwara, and H. Akagi, "Experimental verification of a modular multilevel cascade inverter based on double-star bridge cells," IEEE Trans. Ind. Appl., vol. 50, no. 1, pp. 509-519, Jan./Feb. 2014.

[26] K. Sekiguchi, P. Khamphakdi, M. Hagiwara, and H. Akagi, "A grid-level high-power BTB (back-to-back) system using modular multilevel cascade converters withoutcommon DC-link capacitor," IEEE Trans. Ind. Appl., vol. 50, no. 4, pp. 2648-2659, Jul./Aug. 2014.

[27] J. Ota, Y. Shibano, N. Niimura, and H. Akagi, "A phase-shifted-PWM DSTATCOM using a modular multilevel cascade converter (SSBC)-Part I: Modeling, analysis, and design of current control," IEEE Trans. Ind. Appl., vol. 51, no. 1, pp. 279-288, Jan./Feb. 2014.

[28] M. Hagiwara, R. Maeda, and H. Akagi, "Negative-sequence reactivepower control by a PWM STATCOM based on a modular multileve cascade converter (MMCC-SDBC)," IEEE Trans. Ind. Appl., vol. 48, no. 2, pp. 720-729, Mar./Apr. 2012.

[29] M. Hagiwara, R. Maeda, and H. Akagi, "Control and analysis of the modular multilevel cascade converter based on double-star choppercells (MMCC-DSCC)," IEEE Trans. Power Electron., vol. 26, no. 6 pp. 1649-1658, Jun. 2011.

[30] H. Akagi, "Classification, terminology, and application of the modular multilevel cascade converter (MMCC)," IEEE Trans. Power Electron., vol. 26, no. 11, pp. 3119-3130, Nov. 2011.

[31] M. Hagiwara, R. Maeda, and H. Akagi, "Control and analysis of the modular multilevel cascade converter based on double-star choppercells (MMCC-DSCC)," IEEE Trans. Power Electron., vol. 26, no. 6, pp. 1649-1658, Jun. 2011

[32] M. Vatani, M. Hovd, and M. Saeedifard, "Control of the modular multilevel converter based on a discrete-time bilinear model using the sum of squares decomposition method," IEEE Trans. Power Del., vol. 30, no. 5, pp. 2179-2188, Oct. 2015.

[33] S. Lu, L. Yuan, Z. Zhao, F. C. Lee, and R. Huang, "An energy-based multi-loops control strategy for modular multilevel converter," in Proc. 18th Int. Conf. Electr. Mach. Syst., 2015, pp. 553-558.

[34] A. Jaafar, G. Bergna, J. C. Vannier, and P. Lefranc, "Energy concept-based nonlinear stabilization and control for modular multilevel converters for voltage oscillation reduction," in Proc. 16th Eur. Conf. Power Electron. Appl., 2014, pp. 1-10. 
[35] M. Glinka and R. Marquardt, "A new AC/AC multilevel converter family," IEEE Trans. Ind. Electron., vol. 52, no. 3, pp. 662-669, Jun. 2005.

[36] C. Oates and C. Davidson, "A comparison of two methods of estimating losses in the modular multi-level converter," in Proc. 14th Eur. Conf. Power Electron. Appl., 2011, pp. 1-10.

[37] J. W. Kolar, H. Ertl, and F. C. Zach, "Influence of the modulation method on the conduction and switching losses of a PWM converter system," IEEE Trans. Ind. Appl., vol. 27, no. 6, pp. 1063-1075, Nov./Dec. 1991

[38] T. Jonsson, P. Lundberg, S. Maiti, and Y. Jiang-Häfner, "Converter technologies and functional requirements for reliable and economical HVDC grid design," presented at the Cigre, Canada, CAL, Canada, 2013.

[39] M. K. Bucher and C. M. Franck, "Comparison of fault currents in multiterminal HVDC grids with different grounding schemes," in Proc. IEEE PES Gen. Meeting Conf. Expo., 2014, pp. 1-5.

[40] C. Armschat, M. Dommaschk, V. Hussennether, and T. Westerweller, "Star point reactor," U.S. Patent US20 120120691 A1, May 17, 2012.

[41] G. P. Adam and B. W. Williams, "Half and full-bridge modular multilevel converter models for simulations of full-scale HVDC links and multiterminal DC grids," IEEE J. Emerg. Sel. Topics Power Electron., vol. 2, no. 4, pp. 1089-1108, Dec. 2014.

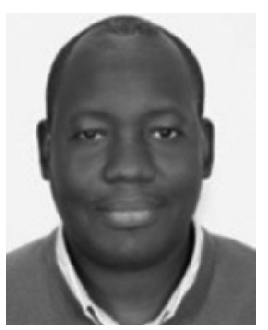

Grain Philip Adam (M'12) received the B.Sc. and M.Sc. (first class) degrees in power systems and electrical machines from Sudan University for Science and Technology, Khartoum, Sudan, in 1998 and 2002, respectively, and the Ph.D. degree in power electronics from University of Strathclyde, Glasgow, U.K., in 2007.

He has been a Research Fellow with the Institute of Energy and Environment, University of Strathclyde, since 2008. He is a visiting Fellow with the University of New South Wales, Sydney, Australia. His research interests include fault-tolerant voltage-source converters for high-voltage directcurrent (HVDC) applications, modeling and control of HVDC transmission systems and multiterminal HVDC networks, voltage-source-converter-based flexible alternating current transmission system devices, and grid integration issues of renewable energies. He has authored and coauthored several technical reports, and journal and conference papers in the area of multilevel converters and HVDC systems, and grid integration of renewable power. Moreover, he has published two books in applications of power electronics in power systems and renewable energy. $\mathrm{He}$ is an active contributor to reviewing process for several IEEE and IET Transactions and Journals and conferences.

Dr. Adam is a member of the IEEE Power Electronics Society.

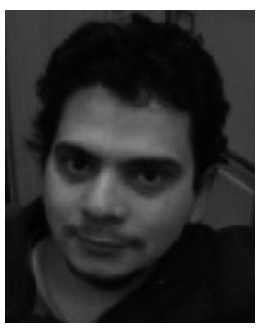

Ibrahim Abdelsalam received the B.Sc. and M.Sc. (first class) degrees in electrical engineering from the Arab Academy for Science and Technology and Maritime Transport, Alexandria, Egypt, in 2006 and 2009 , respectively, and the Ph.D. degree in power electronics from the University of Strathclyde, Glasgow, U.K., 2016.

He is a Lecturer with the Electrical Department, Arab Academy for Science and Technology and Maritime Transport. His research interests include power electronic converters and their applications in wind energy conversion systems, and advanced control strategies of the multilevel voltage and current source converters.

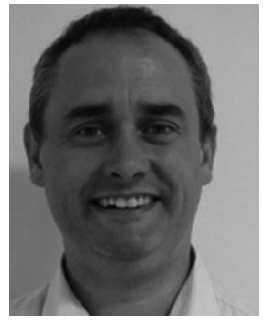

John Edward Fletcher (M'11-SM'13) received the B.Eng. (with first class Hons.) and Ph.D. degrees in electrical and electronic engineering from HeriotWatt University, Edinburgh, U.K., in 1991 and 1995, respectively.

Until 2007, he was a Lecturer at Heriot-Watt University. From 2007 to 2010, he was a Senior Lecturer with the University of Strathclyde, Glasgow, U.K. He is currently a Professor with the University of New South Wales, Sydney, Australia. His research interests include distributed and renewable integration, silicon carbide electronics, pulsed-power applications of power electronics, and the design and control of electrical machines.

Prof. Fletcher is a Charted Engineer in the U.K. and a Fellow of the Institution of Engineering and Technology.

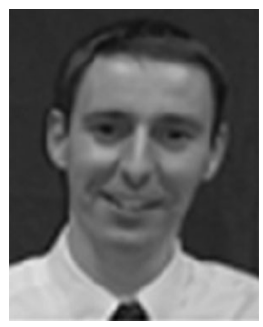

Graeme M. Burt (M'95) received the B.Eng. degree in electrical and electronic engineering, and the Ph.D. degree in fault diagnostics in power system networks from the University of Strathclyde, Glasgow, U.K., in 1988 and 1992, respectively.

He is currently a Professor of electrical power systems at the University of Strathclyde where he co-directs the Institute for Energy and Environment, and directs the Rolls-Royce University Technology Centre in Electrical Power Systems. His research interests include the areas of power system protection and control, distributed energy, and experimental validation.

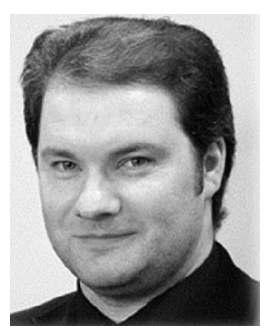

Derrick Holliday received the Ph.D. degree from Heriot-Watt University, Edinburgh, U.K., in 1995.

Since then, he has held full-time academic posts at the University of Bristol and the University of Strathclyde. He has authored or coauthored more than 70 academic journal and conference publications. $\mathrm{He}$ is currently leading industrially funded research in the field of power electronics for high-voltage directcurrent (HVDC) applications and is co-investigator on research programs in the fields of photovoltaic systems and the interface of renewable energy to HVDC systems. His research interests include power electronics, electrical machines, and drives.

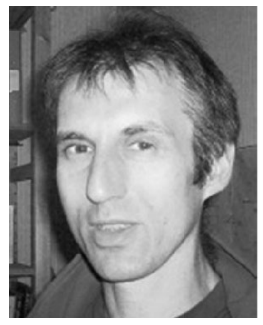

Stephen Jon Finney received the M.Eng. degree in electrical and electronic engineering from Loughborough University, Loughborough, U.K., in 1988. He worked for the Electricity Council Research Centre before joining the Power Electronics Research Group, Heriot-Watt University, Edinburgh, U.K., in 1990, receiving the Ph.D. degree in 1994.

From 1994 to 2005, he was a member of academic staff at Heriot-Watt University. In 2005, he joined the University of Strathclyde, where he is currently a Professor with the Institute of Energy and Environment, specializing in power electronic systems. His research interests include the power electronics for high-power applications and the management of distributed energy resources. 